\title{
Space-Confined Synthesis of CoNi nanoalloy in N-doped Porous Carbon Frameworks as Efficient Oxygen Reduction Catalyst for Neutral and Alkaline Aluminum-air Batteries
}

\begin{abstract}
Exploring efficient and stable non-precious metal electrocatalysts for oxygen reduction reaction in neutral and alkaline solutions is of great importance for metal-air batteries. Herein, an efficient and stable electrocatalyst with CoNi nanoalloy $(10-20 \mathrm{~nm})$ uniformly embedded in porous $\mathrm{N}$ doped carbon framework (CoNi-NCF) for neutral and alkaline primary Al-air batteries is prepared and studied. The CoNi-NCF electrocatalyst shows superior ORR performance in terms of halfwave potential of $0.91 \mathrm{~V}$ in $0.1 \mathrm{M} \mathrm{KOH}$ solution and $0.64 \mathrm{~V}$ in $3.5 \mathrm{wt} \% \mathrm{NaCl}$ solution, outperforming those of the commercial Pt/C catalyst. Supported by in situ electrochemical Raman spectra and density functional theory calculations, the rich dual active sites of CoNi nanoalloy and porous N-doped carbon contributes to the outstanding ORR performance. Impressively, when employed as a cathode catalyst in both aqueous and solid flexible Al-air batteries, the CoNi-NCFbased Al-air batteries show the highest discharge performance, long-time durability and high flexibility, demonstrating the promising potential for practical application.
\end{abstract}

KEYWORDS: CoNi alloy; nitrogen-doped carbon frameworks; oxygen reduction reaction; Insitu Raman; Al-air battery 


\section{Introduction}

Metal-air batteries have been recognized as one of the most promising candidates for possible application in portable electronics, electric vehicles and large-scale energy storage systems due to the high energy density, low cost and environmentally friendly ${ }^{[1,2]}$. In particular, aluminum-air (Al-air) batteries have received tremendous attention for clean and efficient power supply due to the high theoretical energy density $\left(8.1 \mathrm{kWh} \mathrm{kg}^{-1}\right)$, low cost with abundance in nature, negative standard potential and light weight of aluminum ${ }^{[3,4]}$. Typically, Al-air batteries are composed of $\mathrm{Al}$ anodes, air cathodes and electrolytes. Although it is a primary battery, it can be mechanically recharged for continuous discharging by replacing the $\mathrm{Al}$ anodes ${ }^{[5]}$. Al-air primary batteries can be handled in a wide range of electrolytes from neutral saltwater to alkaline solutions. Alkaline solutions are generally used as electrolytes in Al-air batteries for high power delivery. On the other hand, neutral solutions can also be applied in Al-air batteries for emergency lights and undersea power supplies, etc ${ }^{[6]}$. However, the power density of Al-air batteries is still unsatisfied due to the sluggish kinetics of cathodic oxygen reduction reaction (ORR). ORR generally consists of multiple adsorption/desorption reactions involving various oxygen-containing species, and it is expected the ORR undergoes the "four-electron" pathway, leading to a high current efficiency and a large discharge voltage ${ }^{[7-9]}$. Therefore, electrocatalysts are essential for oxygen reduction reaction. ORR catalysts in alkaline solutions have been widely studied, while less progress has been made for developing efficient ORR catalysts under $\mathrm{pH}-$ neutral condition ${ }^{[10]}$. Typically, Ptbased precious metal materials are the best-known efficient ORR electrocatalysts. However, the high cost and natural scarcity as well-known severely suppress the commercialization of metal-air batteries. Additionally, the durability of $\mathrm{Pt} / \mathrm{C}$ is unsatisfied due to the $\mathrm{Pt}$ dissolution and carbon corrosion in strong alkaline medium ${ }^{[11-13]}$. Therefore, it is of great importance to explore highly 
active, stable and low-cost alternatives for ORR in Al-air batteries. Recently, great efforts have been devoted to exploring non-precious-metal electrocatalysts with high performance ${ }^{[14-20]}$.

Among various non-precious-metal alternatives, the extensively studied Pt-free ORR electrocatalysts are metal-nitrogen-carbon (M-N-C, M=Fe, Co, Ni, Mn) materials with metal cations coordinated by pyridinic/pyrrolic nitrogen functionalities in the center or edge of the graphitic matrix ${ }^{[21-23]}$, and studies have demonstrated that $\mathrm{M}-\mathrm{N}_{\mathrm{x}}$ single sites exhibit superior ORR performance ${ }^{[24,25]}$. Although highly catalytic activities comparable to Pt have been achieved, the synthesis of metal-nitrogen-carbon materials with targeted active sites at atomic precision is very difficult and uncontrollable. Recently, bimetallic nanoalloys supported on carbon substrates have also shown efficient ORR electrocatalytic activity due to the synergistic structural and electronic effects of the bimetallic nanoparticles induced by the so-called strain and ligand effects ${ }^{[26,27]}$. However, the half-wave potential of these nanoalloy based catalysts towards ORR is unsatisfied. Additionally, the nanoalloys generally suffer from dissolution into the electrolyte and aggregation during long term cycling, resulting in non-competitive durability. Therefore, it remains a great challenge to synthesize effective and stable multi-metal based electrocatalysts for ORR.

An effective way to increase the active sites and accelerate mass transfer is to embed metal in porous carbon matrix ${ }^{[28,29]}$. The porous carbon matrix can confine the growth of metals and enable active sites fully exposed to the interface, leading to much enhanced ORR performance ${ }^{[30]}$. Metalorganic frameworks (MOFs) are considered as good precursors to prepare carbon matrix ${ }^{[31-33]}$. However, direct pyrolysis usually cause architecture collapse and severe aggregation of metal species during high-temperature calcination ${ }^{[34-37]}$. Therefore, the synthetic strategies of pyrolysis MOF-derived materials needs to be further refined ${ }^{[38]}$. 
Herein, we develop a CoNi bimetal nanoalloy embedded in nitrogen-doped carbon framework (denoted as CoNi-NCF) with the aid of silica stabilization strategy. The silica stabilization favors the CoNi alloy and carbon framework to retain their original size, and the subsequent etching process creates pores in the CoNi-NCF. Benefiting from the active sites of CoNi nanoalloy, large specific surface area, rich pore structure and stable conductive carbon matrix, the CoNi-NCF outperforms the commercial Pt/C towards ORR in both neutral and alkaline electrolytes. The fabricated aqueous and flexible quasi-solid-state Al-air batteries using the CoNi-NCF catalyst demonstrate remarkable battery performance for the practical application. In-situ electrochemical Raman spectroscopy and DFT calculations have identified the active sites of the CoNi alloy, which plays a critical role in boosting the ORR performance.

\section{Experimental section}

\section{Preparation of Ni-ZIF-67@SiO ${ }_{2}$}

2-methylimidazole $(2.70 \mathrm{~g})$ was added into ultra-pure water $(50 \mathrm{~mL})$ with stirring for 10 mins. Then, tetraethyl orthosilicate (TEOS, $0.75 \mathrm{~mL}), \mathrm{Co}\left(\mathrm{NO}_{3}\right)_{2} \cdot 6 \mathrm{H}_{2} \mathrm{O}(0.30 \mathrm{~g})$ and $\mathrm{Ni}\left(\mathrm{NO}_{3}\right)_{2} \cdot 6 \mathrm{H}_{2} \mathrm{O}$ $(0.075 \mathrm{~g})$ dissolved in $25 \mathrm{~mL}$ of water were added to the above solution with continuous stirring for $3 \mathrm{hrs}$ at room temperature. The obtained product denoted as Ni-ZIF-67@ $\mathrm{SiO}_{2}$ was collected after centrifugation, followed by washing with ethanol several times and drying at $60{ }^{\circ} \mathrm{C}$ under vacuum for overnight.

\section{Preparation of CoNi-NCF}

CoNi-NCF@ $\mathrm{SiO}_{2}$ was obtained by the pyrolysis of Ni-ZIF-67@ $\mathrm{SiO}_{2}$ under $\mathrm{N}_{2}$ atmosphere at $900{ }^{\circ} \mathrm{C}$ with a ramp rate of $5{ }^{\circ} \mathrm{C} \mathrm{min}^{-1}$ for $2 \mathrm{hrs}$ in a tube furnace. The obtained CoNi-NCF@ $\mathrm{SiO}_{2}$ was treated with $6 \mathrm{M} \mathrm{NaOH}$ solution for $48 \mathrm{hrs}$ to remove $\mathrm{SiO}_{2}$. The solid material was collected 
by centrifugation, washing with ethanol three times and drying at $60{ }^{\circ} \mathrm{C}$ under vacuum to obtain the CoNi-NCF.

\section{Preparation of CoNi-NC and Co-NC}

2-methylimidazole $(2.70 \mathrm{~g})$ was dissolved in ultra-pure water $(50 \mathrm{~mL})$ with stirring for 10 mins. Then $\mathrm{Co}\left(\mathrm{NO}_{3}\right)_{2} \cdot 6 \mathrm{H}_{2} \mathrm{O}(0.30 \mathrm{~g})$ and $\mathrm{Ni}\left(\mathrm{NO}_{3}\right)_{2} \cdot 6 \mathrm{H}_{2} \mathrm{O}(0.075 \mathrm{~g})$ dissolved in $25 \mathrm{~mL}$ of water were added to the above solution with continuous stirring for $3 \mathrm{hrs}$ at room temperature. The obtained product was collected by centrifugation, followed by washing and drying, and then he CoNi-NC was obtained by the pyrolysis under $\mathrm{N}_{2}$ at $900{ }^{\circ} \mathrm{C}$ with a ramp rate of $5^{\circ} \mathrm{C} \mathrm{min}^{-1}$ for $2 \mathrm{hrs}$ in a tube furnace. The Co-NC was also synthesized with the identical procedure without the addition of $\mathrm{Ni}\left(\mathrm{NO}_{3}\right)_{2} \cdot 6 \mathrm{H}_{2} \mathrm{O}$.

\section{Materials Characterization}

Crystal structures of the as-prepared powder samples were identified using X-ray diffraction (XRD) on a Rigaku Ultima IV diffractometer with $\mathrm{Cu} \mathrm{K} \alpha$ X-ray step-scanning in the $2 \theta$ range of $10-80^{\circ}$. (scanning step $2^{\circ} \min ^{-1}$ ). Raman spectra were collected using a Bruker Senterra R200-L confocus Raman spectrometer (50X objective) using $532 \mathrm{~nm}$ laser light (a laser power of $20 \mathrm{~mW}$ ). X-ray photoelectron spectroscopy (XPS) was undertaken using a Kratos AXIS Ultra DLD with monochromic Al ka X-rays $(1486.7 \mathrm{eV})$ under ultrahigh vacuum condition. $\mathrm{N}_{2}$ isothermal adsorption/desorption was conducted at $77 \mathrm{~K}$ using a Quantachrome Autosorb-1 instrument. Scanning electron microscopy (SEM) images were obtained on an FEI Sirion 200 SEM instrument at a working voltage of $5 \mathrm{kV}$. Electron diffraction patterns, transmission electron microscopy (TEM), high-resolution TEM (HRTEM) images, high angle annular dark field scanning TEM (HAADF-STEM) and energy dispersive X-ray spectra were obtained using TALOS F200X 
instrument with an accelerating voltage of $200 \mathrm{kV}$. Cs-corrected HADDF-STEM images were captured in JEM-ARM200F operated at $200 \mathrm{kV}$ with a minimum probe of $1 \AA$ in diameter.

\section{ORR Electrocatalytic measurements}

Electrochemical measurements of the as-synthesized catalysts were carried out with threeelectrode configuration using Gamry (REF 600), while platinum wire and saturated calomel electrode (in alkaline media) or $\mathrm{Ag} / \mathrm{AgCl}$ electrode (in neutral solution) were used as counter and reference electrodes, respectively. The glassy carbon disk $(5 \mathrm{~mm}$ in diameter, PEEK, PINE Instrument Inc.) was polished with $0.05 \mu \mathrm{m}$ alumina slurry and then sonicated in ultrapure water and ethanol. The catalyst ink was prepared by ultrasonically dispersing $4 \mathrm{mg}$ of electrocatalyst in a mixture of ethanol $(480 \mu \mathrm{L})$ and Nafion $(5 w \mathrm{t} \%, 20 \mu \mathrm{L})$ for $2 \mathrm{hrs}$ to form a homogenous suspension. Then, $10 \mu \mathrm{L}$ of the catalyst ink was drop-casted on the glassy carbon substrate with a loading of $0.40 \mathrm{mg} \mathrm{cm}^{-2}$. All the potentials in this work were converted to the reversible hydrogen

electrode (RHE) reference scale by $E_{(\mathrm{RHE})}=E_{(\mathrm{SCE})}+0.059 \mathrm{pH}+0.241$ or $E_{(\mathrm{RHE})}=E_{(\mathrm{Ag} / \mathrm{AgCl})}+0.059 \mathrm{pH}+0.197$. The electrochemical testing was conducted in $\mathrm{O}_{2}$-saturated or $\mathrm{N}_{2}$-saturated $0.1 \mathrm{M} \mathrm{KOH}$ solution or $3.5 \mathrm{wt} \% \mathrm{NaCl}$ solution. $\mathrm{RDE}$ measurements were carried out at various rotating speeds from 400 to $1600 \mathrm{rpm}$ at a scan rate of $10 \mathrm{mV} \mathrm{s}^{-1}$. EIS tests were performed at an amplitude of $10 \mathrm{mV}$ within the frequency range from $100 \mathrm{kHz}$ to $0.01 \mathrm{~Hz}$.

\section{In-situ electrochemical Raman spectroscopy}

Glassy carbon plate $(1 \mathrm{~cm} * 1 \mathrm{~cm})$ was polished with $0.05 \mu \mathrm{m}$ alumina slurry and followed by rinsing in ultrapure water and ethanol. The catalyst suspension deposited on the glassy carbon substrate to obtain a loading of $1 \mathrm{mg} \mathrm{cm}^{-2}$ and dried at room temperature. The Raman cell was home-made using Teflon as support, and the glassy carbon plate with catalyst was used as working electrode, while a Pt wire counter electrode and a SCE reference electrode were employed. The 
catalyst was faced to the objective of Raman. All measurements were carried out in $\mathrm{O}_{2}$ saturated $0.1 \mathrm{M} \mathrm{KOH}$ solution and $3.5 \mathrm{wt} \% \mathrm{NaCl}$ solution. Raman spectra were collected at various potentials with each test for $100 \mathrm{~s}$ using a Renishaw inVia Qontor confocal Raman microscope (50X objective) using $532 \mathrm{~nm}$ laser light (a laser power of $10 \mathrm{~mW}$ ) with the reaction cell. The diameter of the laser spot was $1 \mu \mathrm{m}$.

\section{Calculation method}

All DFT calculations were based on the density functional theory (DFT) implementing the Vienna Ab-initio Simulation Package (VASP). For details, please refer to the supporting information.

\section{Aqueous Al-air primary battery assembly}

For the cathode preparation, a mixture of the active electrocatalysts, carbon black (Vulcan XC72) and poly(tetrafluoroethylene) (PTFE) (60 wt\% emulsion) with a mass ratio of 20: 60: 20 in ethanol was stirred to form to a film, which was then pressed into the gas diffusion layer (Toray carbon fibre paper) and sintered at $300{ }^{\circ} \mathrm{C}$ for 10 mins. The mass of electrocatalysts in air cathode was $2.5 \mathrm{mg} \mathrm{cm}^{-2}$, while the area of the air cathode is $3.14 \mathrm{~cm}^{2}$. The anode was home-made Al-MgSn alloy plate, which was prepared from the high purity aluminum, magnesium particles and tin particles $(>99.99 \%)$ in the electrical resistance furnace at a temperature of $760 \pm 5{ }^{\circ} \mathrm{C}$. The nominal composition of the Al-Mg-Sn alloys are $1.0 \%$ wt $\mathrm{Mg}-0.1 \%$ wt $\mathrm{Sn}-\mathrm{Al}$. The electrolyte is either $4 \mathrm{M}$ $\mathrm{NaOH}$ solution or $3.5 \mathrm{wt} \% \mathrm{NaCl}$ solution.

\section{Flexible solid-state Al-air battery assembly}

The flexible quasi-solid-state Al-air battery was fabricated using Al-Mg-Sn alloy foil (0.06 mm thickness) anode, air cathode and gel electrolyte with the size of $4 \mathrm{~cm}^{2}$. The polymer electrolyte was prepared as follows: $1.5 \mathrm{~g}$ polyvinyl alcohol (PVA) powder was added into $15 \mathrm{~mL}$ water at $80{ }^{\circ} \mathrm{C}$ under stirring for 2 hours. Then, $5 \mathrm{~mL}$ of $18 \mathrm{M} \mathrm{NaOH}$ added into the electrolyte solution 
was kept stirring at $80^{\circ} \mathrm{C}$ for 30 mins, until the solution became uniform. Then, the solution was poured onto a glass plate and frozen in the refrigerator at $-10{ }^{\circ} \mathrm{C}$ for $4 \mathrm{hrs}$ before use.

\section{Results and discussion}

Figure 1a depicts the schematic illustration of the CoNi nanoalloy embedded in porous nitrogen-doped carbon matrix. Firstly, Ni-ZIF-67 @ $\mathrm{SiO}_{2}$ polyhedrons were prepared via a sol-gel process with the addition of tetraethyl orthosilicate (TEOS), which is extremely important to stabilize the carbon framework. The obtained Ni-ZIF-67@ $\mathrm{SiO}_{2}$ was then calcinated under Ar flow to produce the $\mathrm{CoNi}-\mathrm{NCF} @ \mathrm{SiO}_{2}$. The $\mathrm{SiO}_{2}$ here was functioned as a stabilizer to avoid any collapse of carbon framework and aggregation of CoNi alloy during the high-temperature calcination. Subsequently, the silica was removed by leaching to create pores in the CoNi-NCF. Figure 1b-c presents the representative SEM images of the CoNi-NCF at low and high magnifications. The CoNi-NCF demonstrates a typical rhombic dodecahedral structure with a uniform size of $\sim 1 \mu \mathrm{m}$, and the CoNi alloy nanoparticles are uniformly embedded in the carbon matrix. For comparison, the CoNi-NC and $\mathrm{Co}-\mathrm{NC}$ were prepared without the $\mathrm{SiO}_{2}$ stabilization, and clearly the typical rhombic dodecahedral framework is not retained due to the structure collapse during calcination (Figure 1d, e; Figure S1, Supporting Information). Subsequently, the $\mathrm{SiO}_{2}$ was completely removed by etching to create pores in the CoNi-NCF. The $\mathrm{SiO}_{2}$ here is firstly functioned as the skeleton to stabilize the framework from collapse, then acted as a template to create pores to form porous CoNi-NCF. The unique structure can not only prevent aggregation of CoNi alloy nanoparticles, but also offer a high surface area to expose more active sites. 

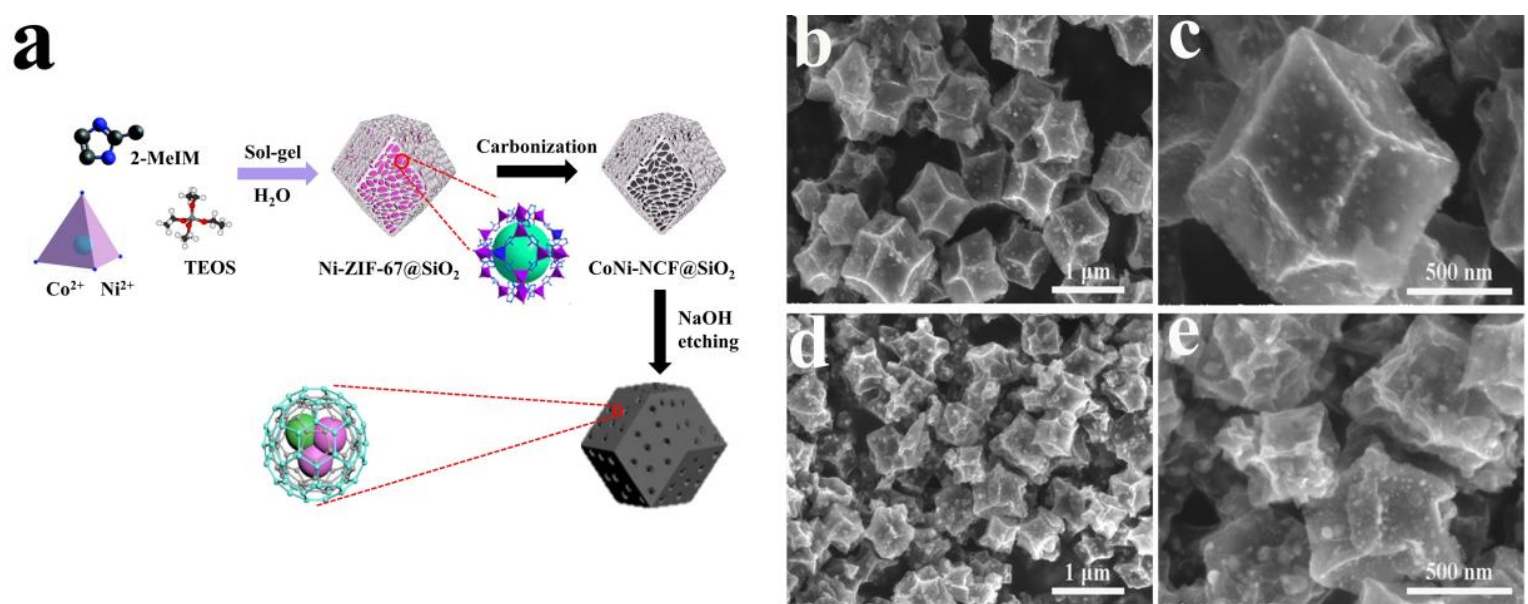

Figure 1. (a) Schematic illustration of the synthesis of CoNi-NCF. SEM images of (b, c) CoNi-NCF and (d, e) CoNi-NC.

To investigate the crystalline structure of the samples, the corresponding XRD patterns are displayed in Figure 2a. The broad diffraction peak at $26.3^{\circ}$ is assigned to the (002) plane of graphitic carbon ${ }^{[1]}$. The additional three diffraction peaks located at $44.5^{\circ}, 51.8^{\circ}$ and $76.2^{\circ}$ of the CoNi-NCF and CoNi-NC samples can easily be assigned to the (111), (200) and (220) planes of face-centered cubic (fcc) CoNi alloy, which are very close but not the same to Co (JCPDS 150806) and Ni (JCPDS 04-0850) metals ${ }^{[39,40]}$. A close observation in the inset shows that the diffraction peak of the alloy locates in the middle between the Co metal and Ni metal diffraction peaks. The calculated cell parameter of CoNi alloy from the XRD is $0.35376 \mathrm{~nm}$, which is larger than $0.35238 \mathrm{~nm}$ for fcc Ni metal and smaller than $0.35447 \mathrm{~nm}$ for fcc Co metal. The result strongly confirms the formation of the CoNi alloy and non-existence of pure cobalt or nickel metal ${ }^{[41]}$. The graphitic nature of Co-NC and CoNi-NCF was corroborated by Raman spectra in Figure S2. All spectra show typical D band and $\mathrm{G}$ band ${ }^{[42,43]}$, and the $\mathrm{D}$ band is associated with the vibrations of the $\mathrm{sp}^{3}$ defective or disordered carbon while the $\mathrm{G}$ band is attributed to the bond stretching of all $\mathrm{sp}^{2}$-bonded pairs ${ }^{[44]}$. The relative ratio of $I_{\mathrm{D}} / I_{\mathrm{G}}$ can be used to estimate the degree of graphitization in the catalyst. The Raman spectrum of CoNi-NCF shows a smaller $I_{\mathrm{D}} / I_{\mathrm{G}}$ value $(0.83)$ than that of 
Co-NC (0.95), indicating the CoNi alloy may facilitate the degree of graphitization ${ }^{[1,45]}$. The electronic structure of the catalysts was further examined by X-ray photoelectron spectroscopy (XPS). The XPS survey spectrum in Figure S3a shows the presence of C, N, Co and Ni in the CoNi-NCF. The deconvoluted N 1s XPS of CoNi-NCF in Figure $2 b$ reveals the presence of pyridinic $\mathrm{N}(1.81 \%)$ at $398.8 \mathrm{eV}$, pyrrolic $\mathrm{N}(1.08 \%)$ at $400.1 \mathrm{eV}$, and graphitic $\mathrm{N}(1.59 \%)$ at 401.3 $\mathrm{eV}^{[46]}$, confirming the successful doping of $\mathrm{N}$ in the carbon matrix. Notably, the total $\mathrm{N}$ content in CoNi-NCF (4.48 at\%) is higher than that in CoNi-NC (1.69 at\%), suggesting that the stable framework could facilitate the $\mathrm{N}$ doping (Figure 2c). Furthermore, the major nitrogen contents in CoNi-NCF are pyridinic $\mathrm{N}$ and graphitic $\mathrm{N}$, which are considered as the decent contributors to $\operatorname{ORR}^{[43,47]}$. The deconvoluted high-resolution C 1s spectrum in Figure S3b suggests C-C (284.6 $\mathrm{eV}), \mathrm{C}=\mathrm{N}(285.4 \mathrm{eV}), \mathrm{C}=\mathrm{O}(286.6 \mathrm{eV})$ and $\mathrm{O}=\mathrm{C}-\mathrm{O}(288.9 \mathrm{eV})$ in the catalyst, further confirming the formation of N-doped carbon ${ }^{[48]}$. Additionally, the XPS of Si in Figure S3c suggests there is a trace amount of $\mathrm{Si}(0.83 \mathrm{wt} \%)$ existed in the catalyst, which is due to the uncompleted remove of $\mathrm{SiO}_{2}$. Figure 2d displays the type IV nitrogen adsorption-desorption curves with $\mathrm{H} 3$ type hysteresis loop, revealing the mesoporous-structure of the catalysts. The Brunauer-Emmett-Teller (BET) surface area of CoNi-NCF is $361.3 \mathrm{~m}^{2} \mathrm{~g}^{-1}$, which is significantly higher than $159.8 \mathrm{~m}^{2} \mathrm{~g}^{-1}$ for CoNi-NC or $225.8 \mathrm{~m}^{2} \mathrm{~g}^{-1}$ for Co-NC. The increase in BET surface area is ascribed to the rich mesopores created by $\mathrm{SiO}_{2}$. In addition, the CoNi-NCF demonstrates larger average pore size than CoNi-NC and Co-NC (Figure S4, Supporting Information). The high surface area and porous architecture of the CoNi-NCF would expose more active sites to access the ORR-relevant species. 

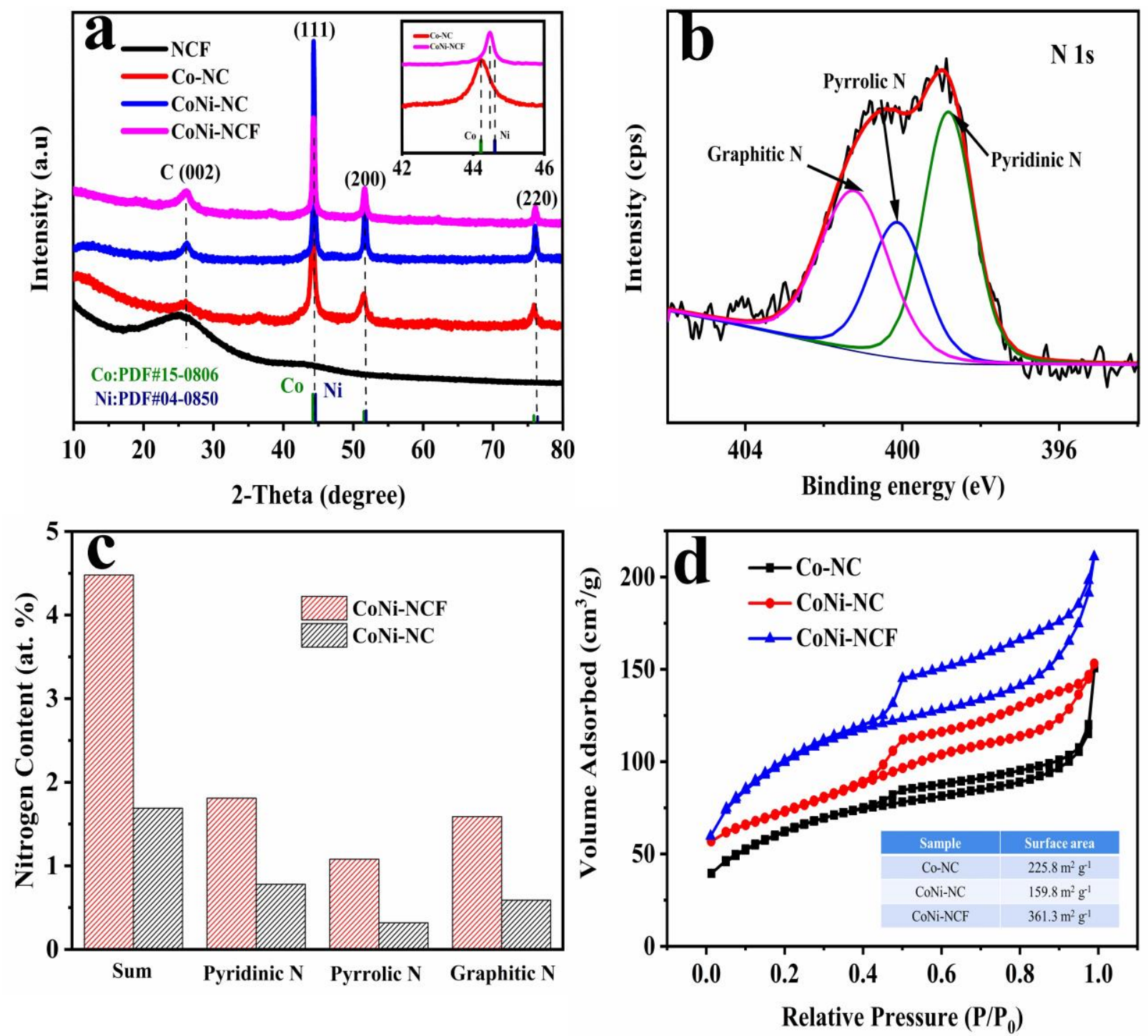

Figure 2. (a) XRD patterns of CoNi-NCF, CoNi-NC, Co-NC and NCF. (b) N 1s XPS of CoNi-NCF. (c) Different $\mathrm{N}$ dopant contents of CoNi-NCF and CoNi-NC. (d) $\mathrm{N}_{2}$ adsorption-desorption isotherms of CoNi-NCF, CoNi$\mathrm{NC}$ and $\mathrm{Co}-\mathrm{NC}$.

The microstructure of the CoNi-NCF was further analyzed. Figure 3a-c shows the transmission electron microscopy (TEM) images of $\mathrm{CoNi}-\mathrm{NCF}$, and the $\mathrm{CoNi}$ alloy nanoparticles with a size of 10-20 $\mathrm{nm}$ are uniformly embedded in nitrogen-doped carbon matrix, which displays very thin graphene-like structure. The high-resolution TEM image in Figure 3d shows the lattice fringe spacings of $0.205 \mathrm{~nm}$ and $0.345 \mathrm{~nm}$ corresponding to the (111) plane of CoNi alloy and the (002) plane of graphitic carbon ${ }^{[49]}$. As the selected area electron diffraction (SAED) shown in Figure 
3e, the interlayer region of CoNi-NCF consists of a fcc phase with the electron incidence parallel to the [011] direction, and the measured lattice distances of 0.205 and $0.177 \mathrm{~nm}$ correspond to the (111) and (200) planes of CoNi alloy, respectively ${ }^{[50]}$, which is consistent with the previous XRD analysis ${ }^{[49]}$. Moreover, the high-angle annular dark-field scanning transmission electron microscopy (HAADF-STEM) image is given in Figure $3 \mathrm{f}$ and the cross- sectional compositional line profiles detected by STEM/energy-dispersive spectroscopy (EDS) are shown in Figure 3g. The black, red, blue and pink lines represent smooth compositional profiles for the $\mathrm{C}, \mathrm{Co}, \mathrm{Ni}$ and $\mathrm{N}$, respectively. The profile analysis indicates that the intensity of Co and $\mathrm{Ni}$ are continuously and uniformly distributed over the carbon frameworks. The elemental mapping images of the CoNiNCF in Figure 3h show that Co, Ni, C and $\mathrm{N}$ elements are evenly distributed in the whole framework, while the non-uniform distribution in the CoNi-NC is observed in Figure S5 for comparison, indicating the homogeneous nitrogen doping and CoNi distribution in the catalyst is due to the silica template stabilization. Furthermore, the Co and Ni contents in the CoNi-NCF were further detected by inductively coupled plasma optical emission spectrometry (ICP-OES), and the Co and $\mathrm{Ni}$ weight fractions are $4.5 \%$ and $1.1 \%$ respectively, giving the molar ratio of Co to $\mathrm{Ni}$ is $\sim 4.1$. Therefore, the CoNi alloy in the CoNi-NCF is denoted as Co4Ni. 


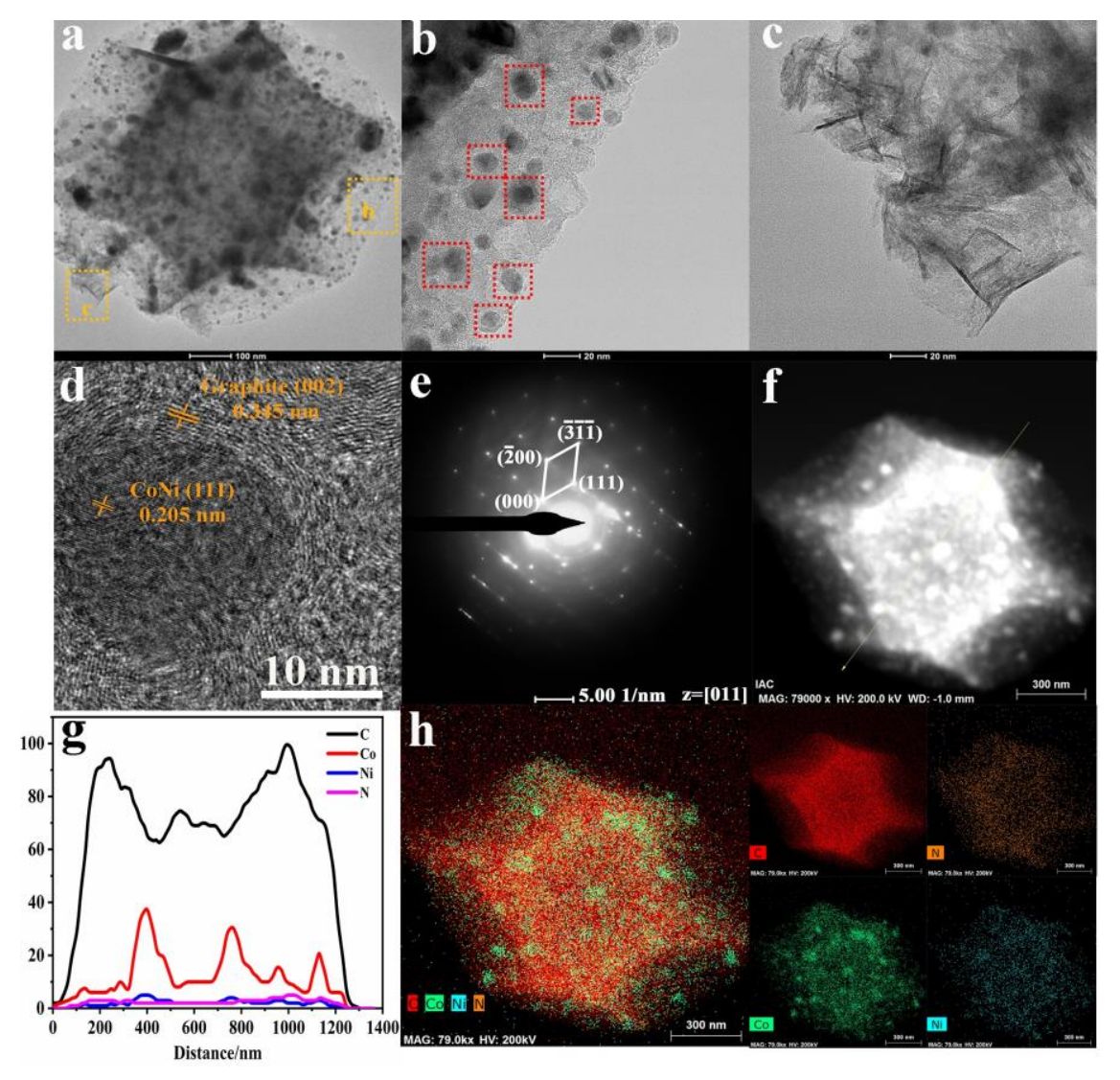

Figure 3. (a-c) TEM images of CoNi-NCF with different magnifications. (d) HRTEM image of CoNi-NCF. (e) SAED pattern of CoNi-NCF. (f) HAADF-STEM image of a single CoNi-NCF particle. (g) Corresponding line scanning profile of CoNi-NCF. (h) Elemental mapping of C, N, Co and Ni.

The structure of the CoNi alloy nanoparticles and the interface between CoNi alloy and N-doped carbon were further investigated. Figure 4a, b display the aberration (Cs) corrected HAADF image of the CoNi-NCF, consisting of CoNi alloy (bright regions) and $\mathrm{N}$ doped carbon (dark regions) [51]. A colored map was created based on the intensity of each atom in Figure 4c, demonstrating the clear difference in contrast between the CoNi alloy and nitrogen doped carbon ${ }^{[52]}$. Figure $4 \mathrm{~d}$ presents the bimetallic nanoparticle, displaying the $d$-spacings of $0.205,0.177$ and $0.125 \mathrm{~nm}$ are ascribed to the (111), (200) and (220) lattice planes of the fcc CoNi alloy with the cell parameter of $0.35384 \mathrm{~nm}^{[53]}$. The FFT in inset obtained from the area marked by the white square further confirms the above fcc crystal structure. This further confirms the formation of the CoNi alloyed structure and non-existence of pure cobalt or nickel metal. In order to analyze the atomic structure, 
the Cs-corrected HAADF image of the CoNi-NCF were processed by filtering and adding false colours based on intensity. As shown in Figure 4e, the atomic structure indicates the Ni atoms are perfectly alloyed with Co atoms. By examining the corresponding intensity profile marked with white rectangle in the inset, the dramatic difference in intensity is observed due to the different atomic number, indicating the alternating of $\mathrm{Co}$ and $\mathrm{Ni}$ atoms in a single atomic column. These results again confirm the formation of the $\mathrm{CoNi}$ alloyed structure. Therefore, Figure $4 \mathrm{f}$ gives the corresponding atomic model of the cubic $\mathrm{Co} 4 \mathrm{Ni}$ alloy.

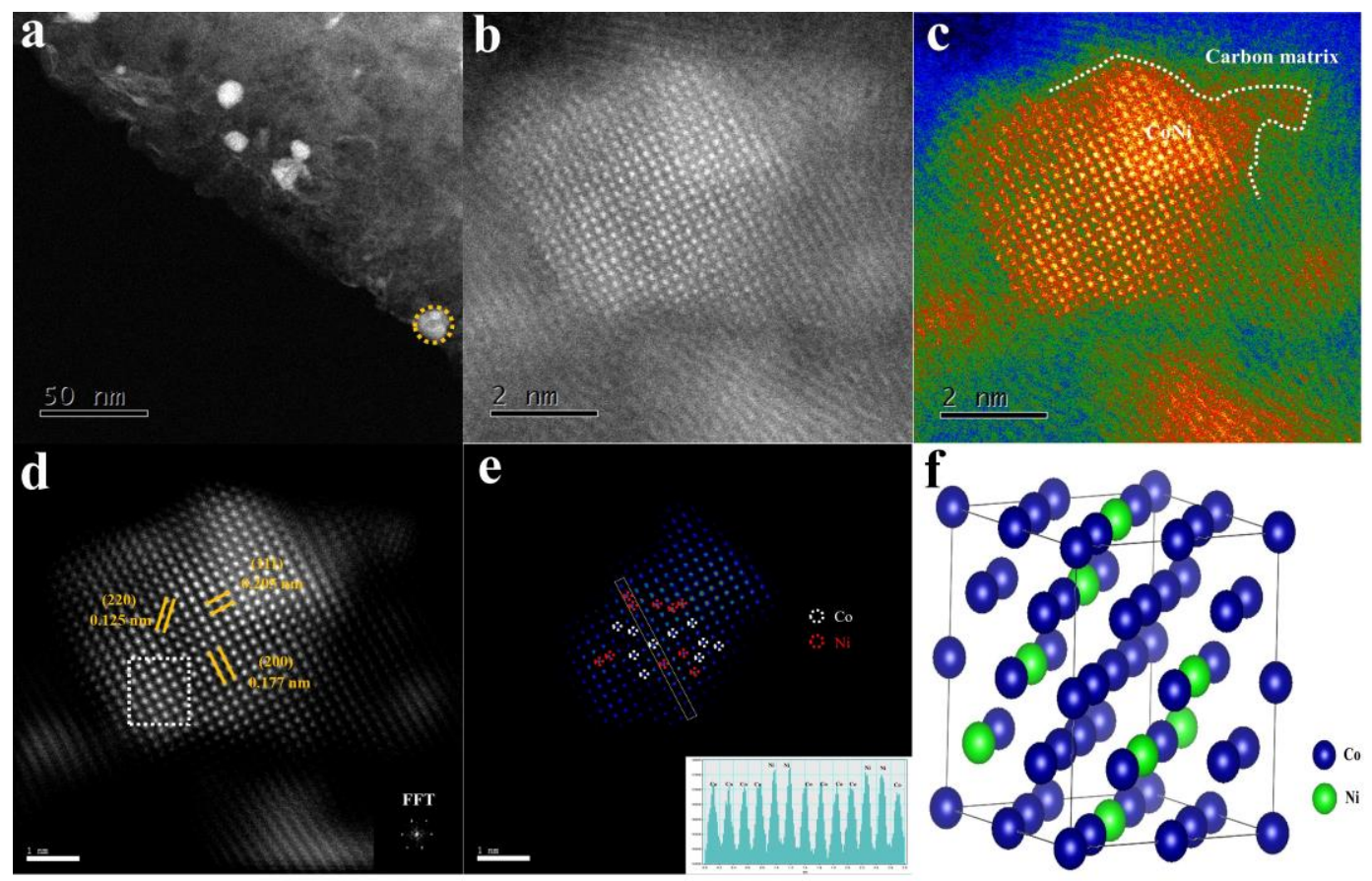

Figure 4. $(\mathrm{a}, \mathrm{b})$ Cs-corrected STEM-HAADF images of bimetallic nanoparticles on the carbon matrix. (c) Artificially colored Cs-corrected STEM micrographs. (d) Atomic resolution Cs-corrected STEM-HAADF images of bimetallic nanoparticles. Inset: FFT image of the area marked with the white rectangle. (e) Colored intensity image of the $\mathrm{CoNi}$ alloy component, depicting the distribution of the Co atoms and $\mathrm{Ni}$ atoms, Inset: the intensity profile corresponding to the line. (f) The atomic structure schematic of the cubic $\mathrm{Co}_{4} \mathrm{Ni}$ alloy.

The CoNi-NCF with dual active sites and a high surface area is expected to possess high ORR performance. Figure 5a shows the CV curves of the CoNi-NCF and commercial Pt/C in both $\mathrm{N}_{2-}$ satured and $\mathrm{O}_{2}$-satured alkaline solutions at a scan rate of $5 \mathrm{mV} \mathrm{s}^{-1}$. Obvious reduction peaks on the $\mathrm{CoNi}-\mathrm{NCF}$ and $\mathrm{Pt} / \mathrm{C}$ catalysts are observed in the $\mathrm{O}_{2}$-satured alkaline solution, clearly 
demonstrating the reduction of oxygen. However, the peak potential on the CoNi-NCF (0.90 V) is more positive than that on Pt/C $(0.83 \mathrm{~V})$, indicating better catalytic activity ${ }^{[35,54]}$. Firstly, the contribution of N-doped of carbon framework to the activity of CoNi-NCF catalyst is clarified. Figure S6 shows the LSV curves of the CoNi-NCF and CoNi-CF catalysts, and clearly the CoNiNCF shows more positive onset and half-wave potentials than the CoNi-CF, confirming that the $\mathrm{N}$-doping can enhance the ORR activity of the CoNi-NCF. To further demonstrate the effectiveness of dual sites in CoNi-NCF, the steady-state LSV curves of the CoNi-NCF and NCF, Co-NC, CoNi-NC as well as commercial Pt/C catalysts are displayed in Figure 5b for comparison. The extracted corresponding onset potential, half-wave potential and limiting current density are listed in Table S1. The CoNi-NC shows more positive onset and half-wave potentials and larger current density than the Co-NC, indicating better ORR catalytic activity. However, the CoNi-NC displays smaller BET surface area than Co-NC shown in Figure 2d, suggesting that CoNi alloy plays an essential role in boosting the ORR activity. Meanwhile, the CoNi-NCF shows better ORR catalytic activity than the CoNi-NC, which is explained by the larger surface area (361.3 vs 159.8 $\mathrm{m}^{2} \mathrm{~g}^{-1}$ ). The larger surface area can expose more active sites to access the ORR-relevant species, resulting in the enhanced ORR performance. Namely, the CoNi-NCF catalyst shows much more positive onset potential $\left(E_{\text {onset }}=1.02 \mathrm{~V}\right)$, half-wave potential $\left(E_{1 / 2}=0.91 \mathrm{~V}\right)$, and larger limiting current density $\left(I_{\text {limiting }}=5.64 \mathrm{~mA} \mathrm{~cm}^{-2}\right)$ than those of the NCF, Co-NC and CoNi-NC, indicating $\mathrm{N}$-doped carbon, CoNi alloy and high surface area contribute to the outstanding activity. Moreover, the CoNi-NCF outperforms the commercial Pt/C, demonstrating outstanding ORR activity of the CoNi-NCF. It's explained that the metal Co incorporated into the $\mathrm{NC}$ can positively shift the onset potential and half-wave potential, and the addition of $\mathrm{Ni}$ to form CoNi alloy can further positively shift the potentials, demonstrating the enhanced ORR performance by the 
incorporation of CoNi alloy, also the robust porous frame structure of NCF can offer more active sites and facilitate electron and mass transfer, resulting in higher ORR activity of CoNi-NCF than CoNi-NC. Figure $5 \mathrm{c}$ shows that the calculated Tafel slope of CoNi-NCF $\left(79 \mathrm{mV}\right.$ decade $\left.^{-1}\right)$ is lower than that of Pt/C (105.0 $\mathrm{mV}$ decade $\left.{ }^{-1}\right)$, further demonstrating the superior electrocatalytic activity of CoNi-NCF ${ }^{[55]}$. The LSV curves of CoNi-NCF at various rotation speeds together with the corresponding Koutecky-Levich (K-L) plots are shown in Figure 5d, and the similar data of the $\mathrm{NCF}, \mathrm{Co}-\mathrm{NC}$ and CoNi-NC are given in Figure S7 as the comparison for better understanding. The electron transfer number of CoNi-NCF calculated from K-L plots is $\sim 4.04$, suggesting a favourable four-electron ORR pathway. Moreover, the electron transfer number is larger than those of the compared catalysts, clearly revealing that the enhanced ORR performance of CoNiNCF is assigned to the bimetallic alloy sites and nitrogen doped carbon frame ${ }^{[49,56,57]}$. In addition, the rotating ring disk electrode (RRDE) test was conducted to further evaluate the ORR catalytic behaviour of CoNi-NCF, CoNi-NC, Co-NC, NCF and Pt/C. Figure 5e shows that the CoNi-NCF catalyst show a lower $\mathrm{HO}_{2}{ }^{-}$yield of below $7 \%$ in the potential range of $0.2-0.8 \mathrm{~V}$ with the higher electron transfer number of 3.82 compared with CoNi-NC, $\mathrm{Co}-\mathrm{NC}, \mathrm{NCF}$ and $\mathrm{Pt} / \mathrm{C}$, which agrees well with K-L plot analysis ${ }^{[58]}$. To exclude any effect of possible $\mathrm{M}-\mathrm{N}_{\mathrm{x}}-\mathrm{C}(\mathrm{M}=\mathrm{Co}$ and $\mathrm{Ni})$ species in the CoNi-NCF, $\mathrm{SCN}^{-}$ions were used to probe any inhibitory effect, as it is documented $\mathrm{SCN}^{-}$ ions can strongly coordinated $\mathrm{M}-\mathrm{N}_{\mathrm{x}}$ species to significantly reduce the catalytic activity ${ }^{[59]}$. Figure 5 f shows that there is almost no change of the LSV curves when adding $5 \mathrm{mM} \mathrm{SCN}^{-}$ions into the electrolyte, suggesting that no $M-N_{x}$ species contribute to the electrocatalytic activity. To further demonstrate the role of the CoNi alloy, the CoNi-NCF was etched in an acid solution to remove the CoNi alloy nanoparticles, and it's observed that the leached sample displays a sharp decline in electrocatalytic activity (Figure 5f). The results here undoubtedly demonstrate that the bi-metallic 
alloy nanoparticles in the CoNi-NCF play a vital role in enhancing the electrocatalytic activity towards ORR.
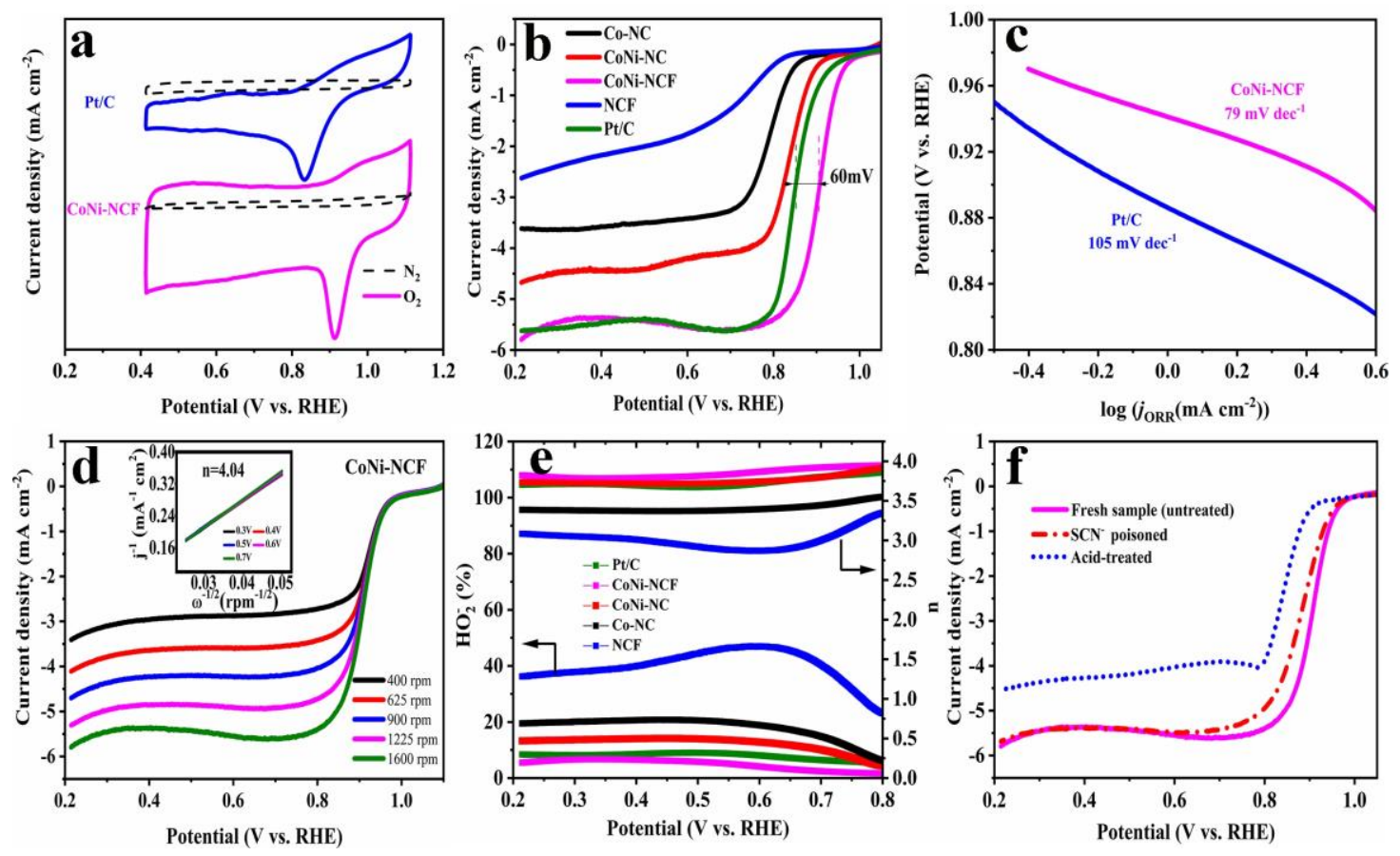

Figure 5. (a) $\mathrm{CV}$ curves of CoNi-NCF and $\mathrm{Pt} / \mathrm{C}$ in $\mathrm{O}_{2}$-saturated and $\mathrm{N}_{2}$-saturated alkaline solutions. (b) LSV curves of Co-NC, CoNi-NC, CoNi-NCF, NCF and Pt/C in $\mathrm{O}_{2}$-saturated $0.1 \mathrm{M} \mathrm{KOH}$ with a scan rate of $10 \mathrm{mV} \mathrm{s}^{-}$ ${ }^{1}$ at $1600 \mathrm{rpm}$. (c) Tafel slopes for CoNi-NCF and Pt/C. (d) LSV curves of CoNi-NCF at various rotation rates and corresponding K-L plots. (e) Peroxide yields and electron number of the CoNi-NCF, CoNi-NC, Co-NC, $\mathrm{NCF}$ and Pt/C calculated from the RRDE in $\mathrm{O}_{2}$-saturated 0.1 M KOH. (f) Effect of acid treatment and $\mathrm{SCN}^{-}$ poisoning on the catalytic activity of CoNi-NCF.

Furthermore, the ORR catalytic performance of the CoNi-NCF was also evaluated in a neutral electrolyte (3.5 wt\% NaCl solution, $\mathrm{pH}=7.0$ ). The $\mathrm{CV}$ curves in Figure 6a shows that the CoNiNCF displays more positive reduction peak potential $(0.58 \mathrm{~V})$ that commercial $\mathrm{Pt} / \mathrm{C}(0.53 \mathrm{~V})$, predicting the effective catalytic activity in the neutral solution. The LSV curves are shown in Figure $6 \mathrm{~b}$, and the onset $\left(E_{\text {onset }}\right)$ and half-wave $\left(E_{1 / 2}\right)$ potentials of CoNi-NCF are $0.82 \mathrm{~V}$ and 0.64 $\mathrm{V}$, respectively, which is more positive than those of $\mathrm{Pt} / \mathrm{C}$ and other catalysts (Table S2, supporting information). Similar to the case in the alkaline solution, the CoNi-NCF also undergoes a nearly four-electron ORR pathway based on the K-L plots (Figure 6c). The RRDE results in Figure 6d 
demonstrates that the $\mathrm{HO}_{2}{ }^{-}$yield on the CoNi-NCF remains below $12 \%$ with the electron transfer number of $\sim 4$, which are much better than those on the Pt/C, CoNi-NC, Co-NC and NCF catalyst. Compared with the alkaline solution, the more sluggish kinetics of ORR in the neutral solution is ascribed to the low concentration of $\mathrm{OH}^{-}$and the $\mathrm{Cl}^{-}$adsorbed on catalysts to block the active sites ${ }^{[60]}$. The results clearly demonstrates better catalytic activity of CoNi-NCF than Pt/C in the 3.5 wt $\% \mathrm{NaCl}$ solution.
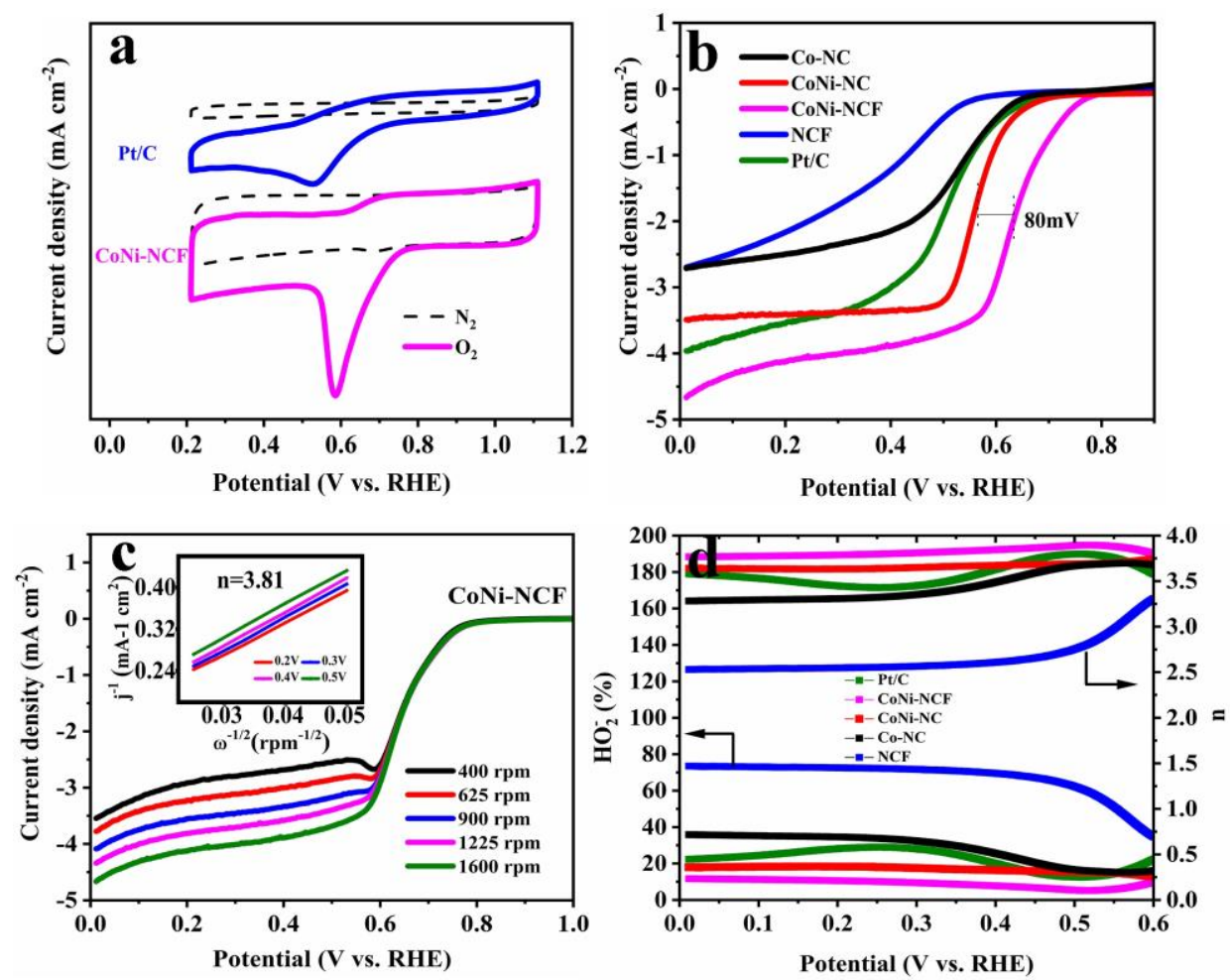

Figure 6. (a) $\mathrm{CV}$ curves of $\mathrm{CoNi}-\mathrm{NCF}$ and $\mathrm{Pt} / \mathrm{C}$ in $\mathrm{O}_{2}$-saturated and $\mathrm{N}_{2}$-saturated $3.5 \mathrm{wt} \% \mathrm{NaCl}$ solutions. (b) LSV curves of Co-NC, CoNi-NC, CoNi-NCF, NCF and $\mathrm{Pt} / \mathrm{C}$ in $\mathrm{O}_{2}$-saturated $3.5 \mathrm{wt} \% \mathrm{NaCl}$ with a scan rate of $10 \mathrm{mV} \mathrm{s}^{-1}$ at $1600 \mathrm{rpm}$. (c) LSV curves of CoNi-NCF at various rotation rates. (d) Peroxide yields and electron numbers of CoNi-NCF, CoNi-NC, Co-NC, NCF and Pt/C based on RRDE data in $\mathrm{O}_{2}$-saturated $\mathrm{NaCl}$ solution.

The long-term durability is also a key parameter to evaluate ORR performance of electrocatalysts. An accelerated durability test (ADT) was performed by potential cycling at a scan rate of $100 \mathrm{mV} \mathrm{s}^{-1}$ for 5000 cycles in both alkaline and neutral solutions. Figure $7 \mathrm{a}, \mathrm{b}$ show the LSV curves before and after ADT are overlapped, indicating the outstanding durability of the 
CoNi-NCF in in both alkaline and neutral electrolytes. To further analyze the long-term durability of the catalyst, the TEM images of CoNi-NCF catalyst after 5000 cycles were collected. Figure 7c-d shows that the robust carbon frameworks remain stable, and the binary CoNi alloy nanoparticles are still homogeneously embedded in the frameworks without any noticeable aggregation ${ }^{[61]}$. Additionally, the electrolyte after 5000 cycles was analyzed by ICP-OES, and no trace of $\mathrm{Co}$ or $\mathrm{Ni}$ was detected, indicating that there is no dissolution of the binary CoNi alloy during the long-term cycling. The results evidence that the CoNi-NCF structure is very stable to offer rich active sites, resulting in outstanding durability.
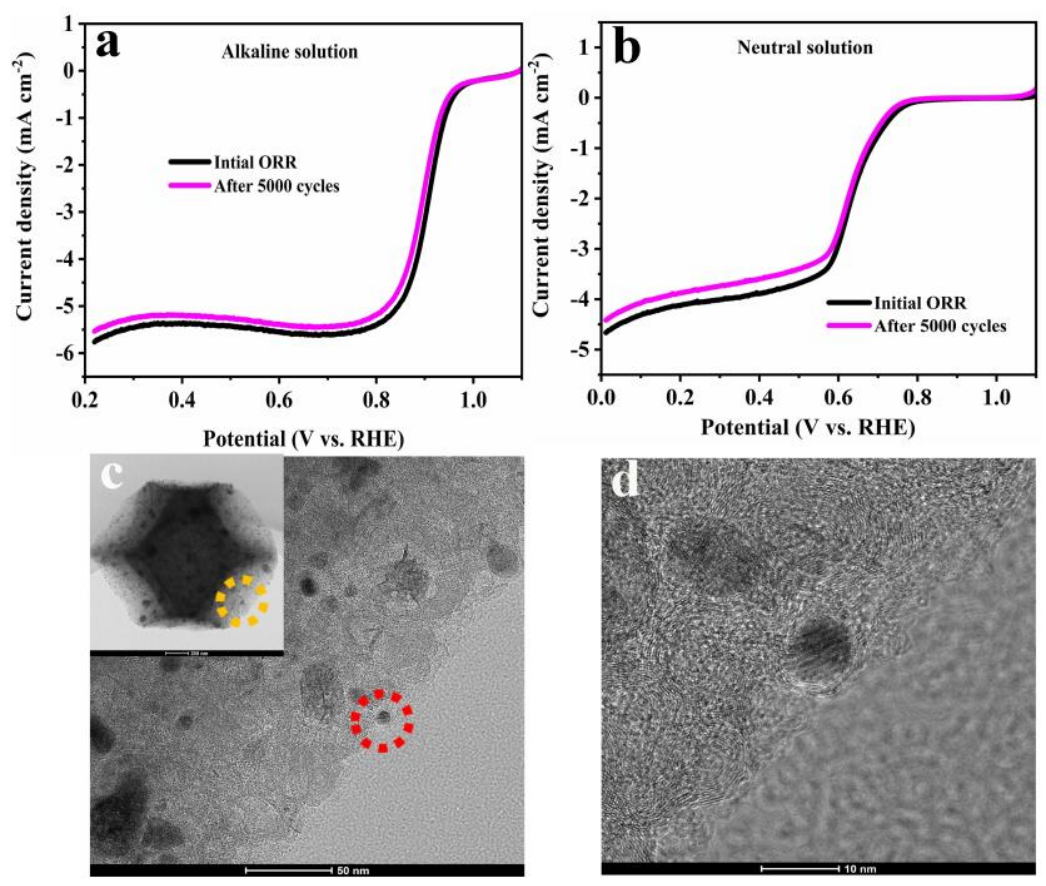

Figure 7. LSV curves of CoNi-NCF before and after $5000^{\text {th }} \mathrm{CV}$ cycles at an RRDE rotation rate of $1600 \mathrm{rpm}$ in $\mathrm{O}_{2}$ saturated (a) $0.1 \mathrm{M} \mathrm{KOH}$ solution and (b) $3.5 \mathrm{wt} \% \mathrm{NaCl}$ solution. (c-d) TEM images of CoNi-NCF after 5000 cycles at different magnifications.

The above results demonstrate the CoNi-NCF catalyst outperforms the commercial Pt/C in terms of onset potential, half-wave potential, limiting current density and long-term durability. The achieved high electrocatalytic performance is ascribed to the following reasons: (1) dual active sites of CoNi nanoalloy and $\mathrm{N}$-doped carbon, (2) high $\mathrm{N}$ doping amount in the carbon, (3) high 
surface area to expose rich active sites, (4) porous and conductive carbon framework in favour of the mass and electron transfer, (5) robust frame structure ensuring no structure collapse during cycling, (6) CoNi nanoalloy embedded in the carbon frames ensuring no aggregation or dissolution during cycling.

The ORR catalytic mechanism on the CoNi-NCF was then monitored by in-situ electrochemical Raman spectroscopy. The Raman spectra were recorded with a house-made electrochemical cell (Figure 8a) using the confocus Raman spectrometer (50X objective, $532 \mathrm{~nm}$ laser light). Figure $8 \mathrm{~b}$ and Figure $\mathrm{S} 8$ show the Raman spectra of the CoNi-CNF polarized at different potentials in $\mathrm{O}_{2}$ saturated neutral and alkaline solutions. When the as-prepared CoNi-NCF electrode was immersed in the $\mathrm{O}_{2}$ saturated electrolyte as the initial state, two peaks are observed at 384 and $691 \mathrm{~cm}^{-1}$, corresponding to the adsorption of $\mathrm{OH}$ species on the catalyst surface to form $\mathrm{Ni}{ }^{\mathrm{II}}-\mathrm{O} / \mathrm{Co}^{\mathrm{II}}-\mathrm{O}^{[62,63]}$. When applying a potential of $0.86 \mathrm{~V}$ in a neutral solution (or $1.11 \mathrm{~V}$ in an alkaline solution, Figure S8), the Raman spectrum is similar to that of the initial state, as there is no oxygen reduction reaction occurred. When applying a relatively negative potential of $0.76 \mathrm{~V}$ in the neutral solution (or $1.01 \mathrm{~V}$ in the alkaline solution), the oxygen reduction is triggered, and two additional Raman bands appear at 500 and $630 \mathrm{~cm}^{-1}$, which are assigned to the formation of $\mathrm{Co}^{\mathrm{III}}-\mathrm{O} / \mathrm{Ni}^{\mathrm{III}}-\mathrm{O}$ species ${ }^{[64-66]}$. With the increase in overpotential, the bands for $\mathrm{Ni}^{\mathrm{II}}-\mathrm{O} / \mathrm{Co}^{\mathrm{II}}-\mathrm{O}$ gradually disappear and the intensities of $\mathrm{Co}^{\mathrm{III}}-\mathrm{O} / \mathrm{Ni}^{\mathrm{III}}-\mathrm{O}$ gradually increase due to the conversion of $\mathrm{Co}^{\mathrm{II}} / \mathrm{Ni}^{\mathrm{II}}$ to $\mathrm{Co}^{\mathrm{III}} / \mathrm{Ni}^{\mathrm{III}}$ species during the ORR. In addition, the peak at $802 \mathrm{~cm}^{-1}$ is ascribed to asymmetric stretching modes of oxygen in binding O-M-O bond ( $\mathrm{M}=\mathrm{CoNi}$ alloy), implying $\mathrm{Co}-\mathrm{O} / \mathrm{Ni}-\mathrm{O}$ units as the ORR active sites. Meanwhile, another new band observed at $730 \mathrm{~cm}^{-1}$ is assigned to the $\mathrm{O}-\mathrm{O}$ stretching vibration due to the presence of oxygen intermediates $\mathrm{OOH}^{*}$, which is considered as an important intermediate during the ORR process ${ }^{[67]}$. With the increase in overpotential, the intensities of those 
peaks increase, indicating much more accumulation of oxygen intermediates (Figure $8 \mathrm{c}$ ) ${ }^{[68]}$. When shifting the potential back to $0.86 \mathrm{~V}$ in the neutral solution (or $1.11 \mathrm{~V}$ in the alkaline solution), the Raman bands for the $\mathrm{Co}^{\mathrm{III}}-\mathrm{O} / \mathrm{Ni}^{\mathrm{III}}-\mathrm{O}$ and $\mathrm{OOH}^{*}$ completely disappear. Based on the in-situ Raman spectra, the $\mathrm{Co}^{\mathrm{III}}-\mathrm{O} / \mathrm{Ni}^{\mathrm{III}}-\mathrm{O}$ and $\mathrm{OOH}^{*}$ intermediates are the main oxygen species during the $\mathrm{ORR}$ process. The ORR mechanism on CoNi-NCF in neutral and alkaline solution is then proposed in Figure 8d. Firstly, $\mathrm{OH}$ species are adsorbed on the catalyst surface to form $\mathrm{M}_{-} \mathrm{OH}^{-}$, and then the $\mathrm{M}-\mathrm{OH}^{-}$species interact with $\mathrm{O}_{2}$ to generate $\mathrm{M}-\mathrm{O}-\mathrm{O}^{2-}$ and $\mathrm{OH}^{-}$. The $\mathrm{M}-\mathrm{O}-\mathrm{O}^{2-}$ species can further reacts with $\mathrm{H}_{2} \mathrm{O}$ and accept electron to form $\mathrm{M}-\mathrm{O}-\mathrm{OH}$ species. Then the $\mathrm{M}-\mathrm{O}-\mathrm{OH}$ further receive electron to form $\mathrm{M}-\mathrm{O}^{2-}$ intermediate. Finally, the $\mathrm{M}-\mathrm{O}^{2-}$ species further react with $\mathrm{H}_{2} \mathrm{O}$ to generate $\mathrm{M}-\mathrm{OH}^{-}$and release $\mathrm{OH}^{-}$.
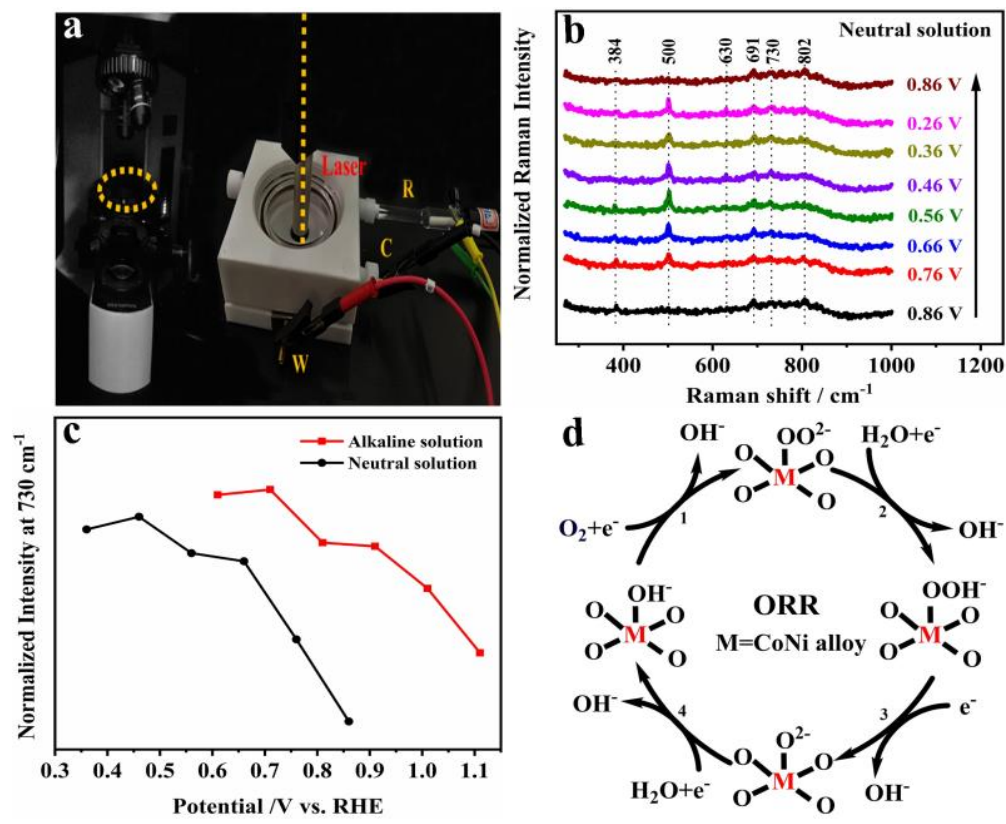

Figure 8. (a, b) Potential-dependent in-situ Raman spectra analysis during the ORR process in alkaline and neutral solution. (c) Normalized Raman Intensities of the stretching mode of $\mathrm{OOH}$ at $730 \mathrm{~cm}^{-1}$. (d) Proposed reaction mechanism.

To further study the origin of the CoNi@ NCF catalytic activity and understand the role of CoNi alloy in the catalytic process, DFT calculations were performed. The interface between the CoNi 
alloy and $\mathrm{N}$-doped carbon was applied in the computational models, considering the $\mathrm{CoNi}$ alloy is embedded in the NCF (Figure S9, Supporting Information). The modelled NCF-adsorbate, Co@NCF-adsorbate and CoNi@NCF-adsorbate are shown in Figure 9a, and the binding free energies of the reaction intermediates were examined. For the NCF, the binding free energies of $\mathrm{OOH}^{*}, \mathrm{O}^{*}$ and $\mathrm{OH}^{*}$ on the NCF surface are 4.43, 2.93 and $0.95 \mathrm{eV}$. For Co-NCF surface, the binding free energies of $\mathrm{OOH}^{*}, \mathrm{O}^{*}$ and $\mathrm{OH}^{*}$ are 3.63, 2.58 and $0.79 \mathrm{eV}$. For CoNi-NCF, the binding free energies of $\mathrm{OOH}^{*}, \mathrm{O}^{*}$ and $\mathrm{OH}^{*}$ are $3.76,2.81$ and $0.87 \mathrm{eV}$, which are close to that of an ideal catalyst for ORR. The computed free energy of all elementary steps as a function of electrode potential $\mathrm{U}$ is shown in Figure 9b. It's shown that some of the elementary reactions along the $4 \mathrm{e}^{-}$pathway are endergonic and thus thermodynamically unfavorable at $\mathrm{U}=1.23 \mathrm{~V}$ (with reference to the RHE), which is zero overpotential. Meanwhile, at $\mathrm{U}=0 \mathrm{~V}$, all the elementary reactions along the $4 \mathrm{e}^{-}$pathway on CoNi-NCF are exothermic. The limiting potential $\mathrm{U}_{\text {limiting }}$ (maximum external potential) at which all the ORR elementary steps on CoNi-NCF are still exothermic is as high as $0.87 \mathrm{~V}$, which is very close to the measured half-wave potential. This calculated value is more positive than those on NCF $(0.45 \mathrm{~V})$ and Co-NCF $(0.79 \mathrm{~V})$, indicating the catalytic ORR performance increasing in the order of $\mathrm{CoNi}-\mathrm{NCF}>\mathrm{Co}-\mathrm{NCF}>\mathrm{NCF}$. Moreover, the CoNi-NCF displays more positive $\mathrm{U}_{\text {limiting }}(0.87 \mathrm{~V})$ than $\mathrm{Pt}(0.79 \mathrm{~V})^{[69]}$, demonstrating superior catalytic activity. The DFT calculations well agree with the experimental results, highlighting the crucial role of the CoNi alloy in the catalytic process. Thus, the combined activation of the CoNi alloy and $\mathrm{N}$ doped carbon contributes to the superior electrocatalytic performance. 

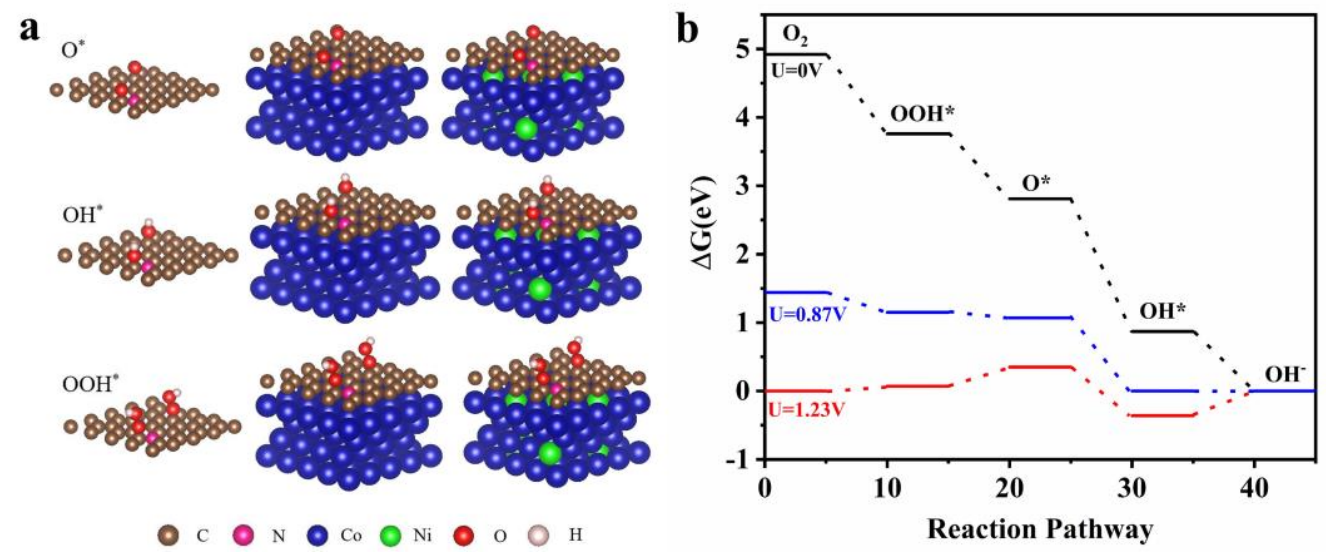

Figure 9. (a) Optimized structures of $\mathrm{OH}^{*}, \mathrm{O}^{*}$, and $\mathrm{OOH}^{*}$ intermediates on $\mathrm{NCF}, \mathrm{Co} @ \mathrm{NCF}$ and $\mathrm{CoNi} @ \mathrm{NCF}$ surfaces. (b) The free-energy landscape of the ${ }^{*} \mathrm{OOH},{ }^{*} \mathrm{O},{ }^{*} \mathrm{OH}$ intermediates in the standard $4 \mathrm{e}^{-}$reactionpathway for ORR catalyzed by CoNi@NCF at zero potential (black), equilibrium potential (red) and limiting potential (blue).

To identify the practical application of the catalysts in air cathodes, house-made Al-air primary batteries schematized in Figure S10 were fabricated using both alkaline and neutral electrolytes.

Figure 10a shows the discharge curves of the alkaline Al-air batteries based on CoNi-NCF and $\mathrm{Pt} / \mathrm{C}$ catalysts at low and high discharge current densities $\left(20\right.$ and $\left.100 \mathrm{~mA} \mathrm{~cm}^{-2}\right)$ for $8 \mathrm{hrs}$. The Alair battery with CoNi-NCF catalyst displays a larger working voltage (1.6 V) than that with $20 \%$ $\mathrm{Pt} / \mathrm{C}$ at both current densities. Moreover, the Al-air battery with CoNi-NCF delivers a more stable discharge voltage at both current densities compared with that using $20 \% \mathrm{Pt} / \mathrm{C}$, demonstrating better catalytic durability in the practical metal-air batteries. The working voltage and power density as a function of current density shown in Figure 10b reveal that the maximum power density of the Al-air battery with CoNi-NCF is $203.7 \mathrm{~mW} \mathrm{~cm}^{-2}$, which is higher than $180.7 \mathrm{~mW}$ $\mathrm{cm}^{-2}$ for that with commercial Pt/C. Electrochemical impedance spectroscopy (EIS) is a powerful technique to evaluate internal resistance and charge transfer resistance. Figure S11 shows the Nyquist plots of the Al-air batteries based on CoNi-NCF and 20\% Pt/C catalysts in the $4 \mathrm{M} \mathrm{NaOH}$ solution. Both plots display similar shape, consisting of a semicircle in the high frequency region and an inclined line in the low frequency region. The Nyquist plot was also fitted via Gamry Echem 
Analyst software following the equivalent circuit given in the inset, and the internal resistance $\left(R_{\mathrm{S}}\right)$ and charge transfer resistance $\left(R_{\mathrm{ct}}\right)$ can be extracted from the intercept at the real axis and the diameter of the semicircle. The fitted $R_{\mathrm{s}}$ and $R_{\mathrm{ct}}$ values for the Al-air battery with CoNi-NCF are $0.50 \Omega$ and $0.48 \Omega$, which are lower than $0.86 \Omega$ and $0.83 \Omega$ for the Al-air battery with Pt/C. The result further confirms the better performance of the CoNi-NCF air cathode than the Pt/C cathode for practical application. A promising feature of Al-air batteries is that they can be mechanically recharged for continuous discharging by replacing the Al alloy plate anode. Figure 10c demonstrates the Al-air battery based on CoNi-NCF displays continuous discharge without any significant voltage decay after refilling $\mathrm{Al}$ alloy plates, demonstrating that the CoNi-NCF catalyst for ORR possesses excellent durability and can be used for ultra-long time discharge for practical application. The demonstration of two Al-air batteries with CoNi-NCF air cathode in series shown in Figure 10d is charging a mobile phone, demonstrating the capability of the Al-air battery with CoNi-NCF electrocatalyst for the realistic power supply application.
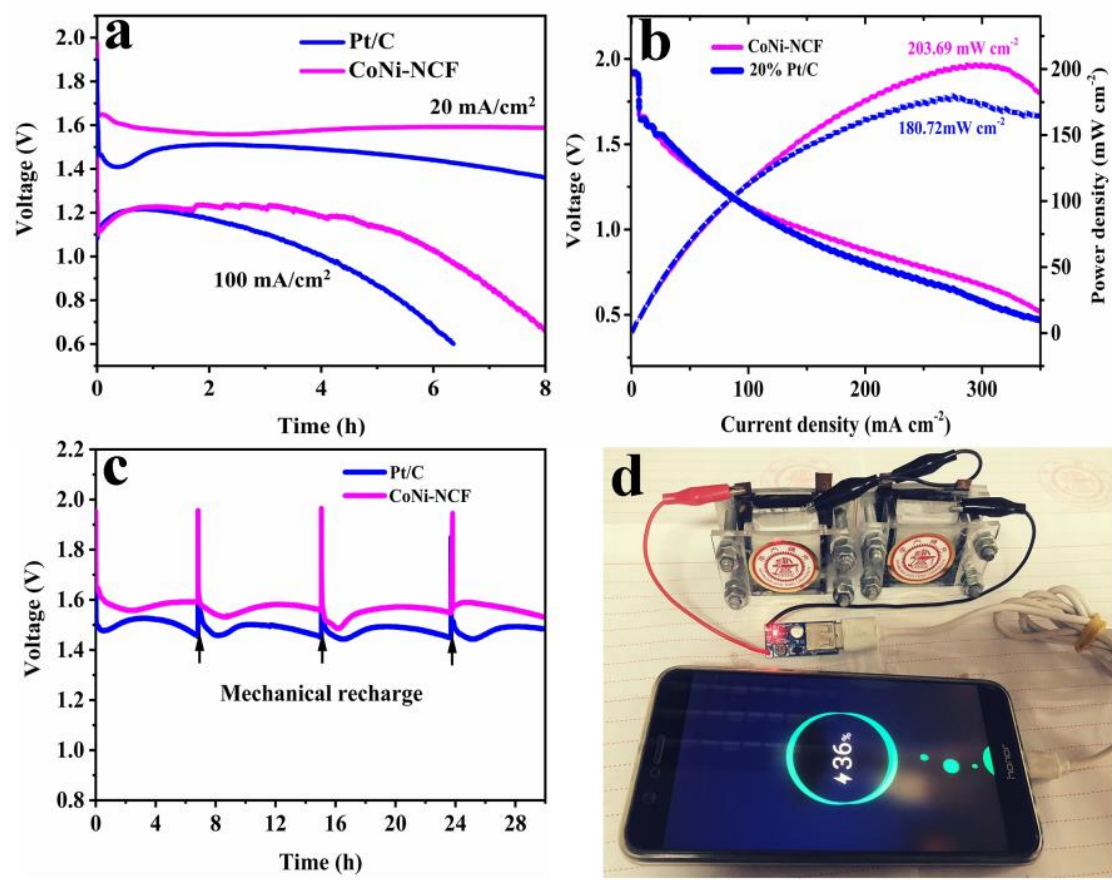
Figure 10. (a) Discharge curves of Al-air batteries in alkaline solution using CoNi-NCF and $20 \% \mathrm{Pt} / \mathrm{C}$ catalysts at current densities of 20 and $100 \mathrm{~mA} \mathrm{~cm}^{-2}$. (b) Polarization and power density curves. (c) Discharge voltage with alternatively mechanical recharge of the Al-air batteries using CoNi-NCF and 20\% Pt/C catalysts. (d) The aqueous Al-air batteries in two series charging a mobile phone.

Figure 11a displays the discharge curves of neutral Al-air batteries at low and high discharge current densities $\left(5\right.$ and $20 \mathrm{~mA} \mathrm{~cm}^{-2}$ ) for $8 \mathrm{hrs}$. The Al-air battery with CoNi-NCF catalyst displays a larger working voltage than that with $20 \% \mathrm{Pt} / \mathrm{C}$ at both current densities. As shown in Figure 11b, the Al-air battery with CoNi-NCF presents a maximum power density of $21.50 \mathrm{~mW} \mathrm{~cm}^{-2}$, which is superior to that of the commercial $\mathrm{Pt} / \mathrm{C}\left(19.06 \mathrm{~mW} \mathrm{~cm}^{-2}\right)$. Moreover, the neutral Al-air batteries can also be mechanically recharged to allow continuous discharging. Figure 11c shows that the Al-air battery based on CoNi-NCF demonstrates continuous discharge without any significant voltage decay, suggesting the better durability upon long-term operation than that of $\mathrm{Pt} / \mathrm{C}$. Figure 11d demonstrates the practical application of the neutral Al-air battery, and the Al-air batteries in two series can run the USB fan.
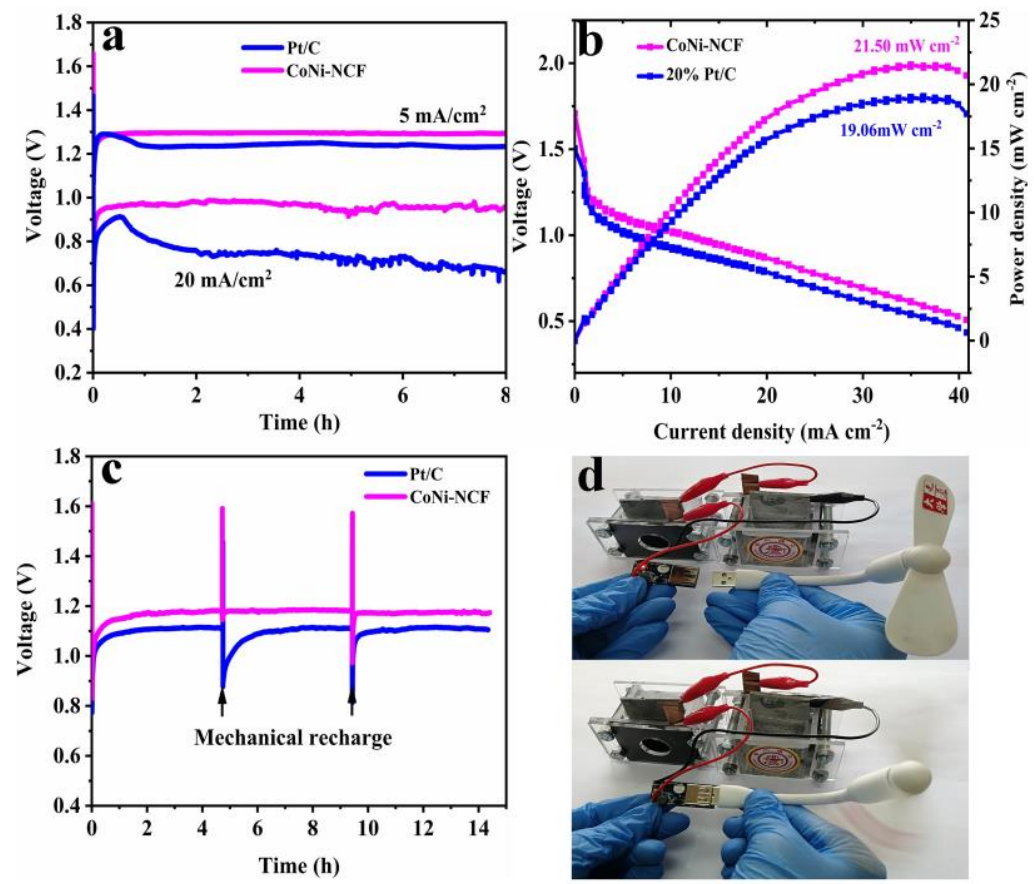

Figure 11. (a) Discharge curves of Al-air batteries in neutral solution using CoNi-NCF and $20 \% \mathrm{Pt} / \mathrm{C}$ catalysts at current densities of 5 and $20 \mathrm{~mA} \mathrm{~cm}^{-2}$. (b) Polarization and power density curves. (c) Discharge voltage with 
alternatively mechanical recharge of the $\mathrm{Al}$-air batteries using CoNi-NCF and 20\% Pt/C catalysts. (d) The USB fan power by two aqueous Al-air batteries.

Apart from aqueous Al-air batteries, flexible quasi-solid-state Al-air batteries were also fabricated using the CoNi-NCF coated on carbon cloth as flexible air-cathode, Al-Mg-Sn foil anode and PVA gel electrolyte to illustrate the potential application in portable and flexible electronic devices. The schematic structure of the flexible quasi-solid-state Al-air battery is shown in Figure 12a and the fabricated flexible Al-air battery delivers a stable working voltage of $\sim 1.8$ $\mathrm{V}$ at a current density of $1 \mathrm{~mA} \mathrm{~cm}{ }^{-2}$, which is comparable to the commercial $\mathrm{Pt} / \mathrm{C}$ catalyst (Figure 12b). The discharge curve at various current densities is shown in Figure 12c and the flexible quasi-solid-state Al-air battery still delivers a stable voltage of $1.29 \mathrm{~V}$ at a current density to $4 \mathrm{~mA}$ $\mathrm{cm}^{-2}$. When switching back to $0.5 \mathrm{~mA} \mathrm{~cm}^{-2}$, the voltage is recovered to the initial state at $0.5 \mathrm{~mA}$ $\mathrm{cm}^{-2}$, indicating good durability. The flexibility of the Al-air battery at various bending angles is demonstrated in Figure 12d and the discharge curves remain almost the same under different bending states, suggesting the good flexibility of the battery with CoNi-NCF catalyst. Additionally, Figure 10e shows the flexible Al-air batteries in series displays a high open-circuit voltage of 3.49 V. Figure 10f shows that two batteries connected in series can light up 65 LEDs with "SJTU" shape under both bending and non-bending states, implying the Al-air batteries are also promising for flexible power sources. 

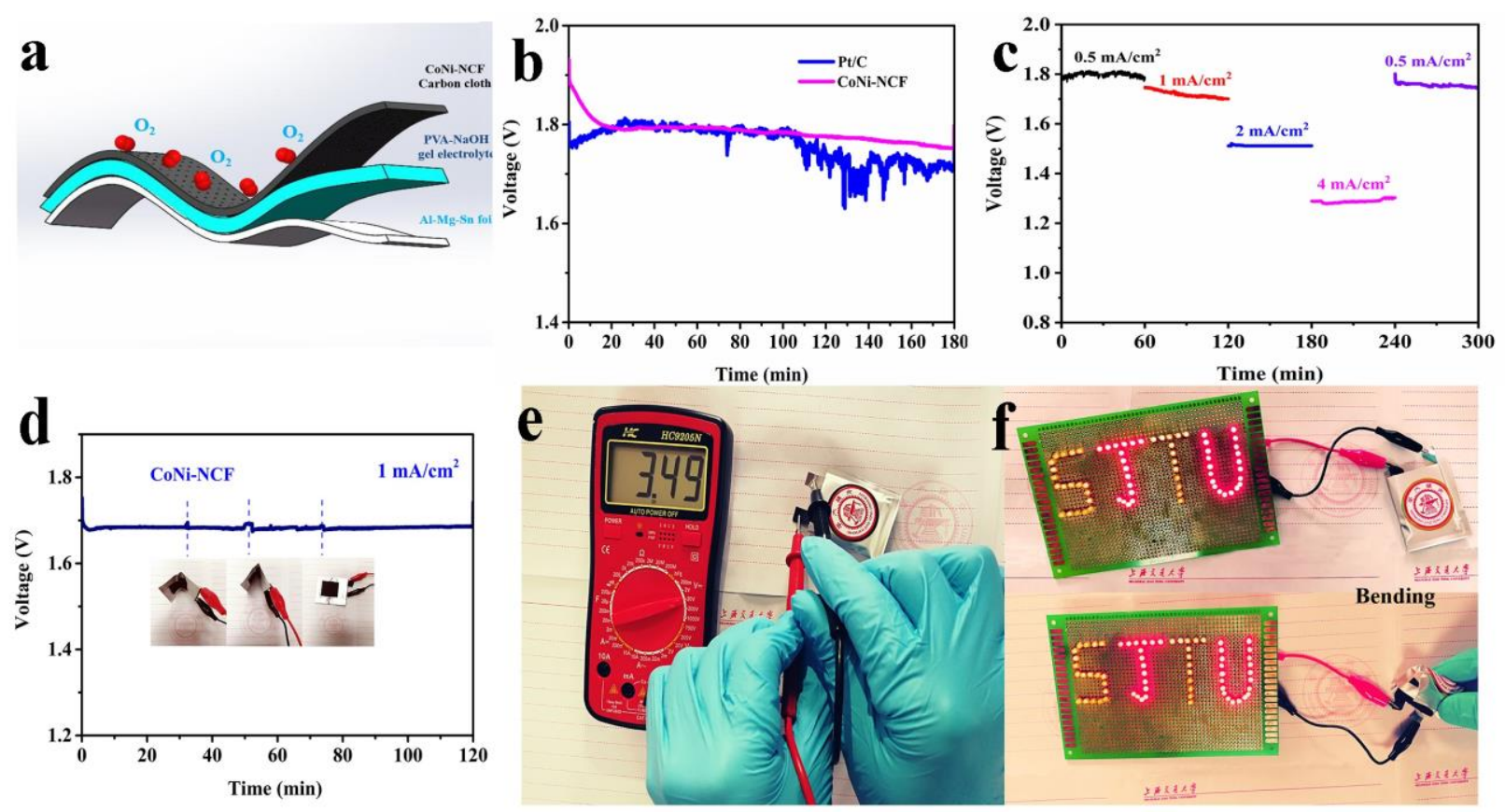

Figure 12. (a) Schematic illustration of the flexible quasi-solid-state Al-air battery. (b) Discharge curves of the quasi-solid-state Al-air batteries with CoNi-NCF and Pt/C cathodes at a current density of $1 \mathrm{~mA} \mathrm{~cm}^{-2}$. (c) Discharge curve of the quasi-solid-state Al-air battery with CoNi-NCF cathode at different current densities. (d) Discharge curve of the quasi-solid-state Al-air battery at different bending angles. (e) Open-circuit voltage of the two serially connected quasi-solid-state Al-air batteries. (f) The solid-state flexible Al-air batteries in two series powered 65 LEDs with "SJTU" shape under both bending and non-bending states.

\section{Conclusions}

In summary, we have developed an efficient and stable electrocatalyst for ORR with porous nitrogen-doped carbon stabilized CoNi nanoalloy via the aid of in-situ formed silica. Benefiting from the rich dual active sites of $\mathrm{CoNi}$ nanoalloy and porous $\mathrm{N}$-doped carbon matrix, the CoNiNCF electrocatalyst outperforms the commercial Pt/C towards ORR in both neutral and alkaline electrolytes. Furthermore, the ORR process on the CoNi-NCF has been revealed by in situ electrochemical Raman spectroscopy, confirming the main intermediates are $\mathrm{Co}{ }^{\mathrm{III}}-\mathrm{O} / \mathrm{Ni}^{\mathrm{III}}-\mathrm{O}$ and $\mathrm{OOH}^{*}$. DFT calculations further confirm the superior activity of CoNi-NCF electrocatalyst attributed to the bimetal CoNi nanoparticle and porous N-doped carbon framework. Additionally, the CoNi-NCF-based air cathode is employed in both aqueous Al-air batteries and quasi-solidstate flexible Al-air batteries, high power density and superior durability are displayed, and good 
flexibility is also demonstrated. This work presents the inspiration for the synthesis of efficient metal-embedded carbon electrocatalysts to substitute Pt/C towards ORR for metal-air batteries.

\section{Acknowledgements}

This work was supported by the National Natural Science Foundation of China (51874197, 51704106). The authors gratefully acknowledge the facilities and technical assistance at Instrumental Analysis Center of SJTU.

\section{Supporting Information}

The Supporting Information is available free of charge on the Elsevier Publications website. Additional experimental data, including SEM, TEM, XPS, LSV, DFT-calculated structures and tables.

\section{Notes}

The authors declare no conflict of interest.

\section{References}

[1] C. Hang, J. Zhang, J. Zhu, W. Li, Z. Kou, Y. Huang, In Situ Exfoliating and Generating Active Sites on Graphene Nanosheets Strongly Coupled with Carbon Fiber toward Self-Standing Bifunctional Cathode for Rechargeable Zn-Air Batteries, Adv. Energy Mater. 8 (2018) 1703539. [2] J.J. Xu, Z.W. Chang, Y. Wang, D.P. Liu, Y. Zhang, X.B. Zhang, Cathode Surface-Induced, Solvation-Mediated, Micrometer-Sized $\mathrm{Li}_{2} \mathrm{O}_{2}$ Cycling for $\mathrm{Li}-\mathrm{O}_{2}$ Batteries, Adv. Mater. 28 (2016) 9620-9628.

[3] I.J. Park, S.R. Choi, J.G. Kim, Aluminum anode for aluminum-air battery-Part II: Influence of In addition on the electrochemical characteristics of Al-Zn alloy in alkaline solution, J. Power Sources, 357 (2017) 47-55. 
[4] B.J. Hopkins, Y. Shao-Horn, D.P. Hart, Suppressing corrosion in primary aluminum-air batteries via oil displacement, Science, 362 (2018) 658-661.

[5] S. Xu, Z. Li, Y. Ji, S. Wang, X. Yin, Y. Wang, A novel cathode catalyst for aluminum-air fuel cells: Activity and durability of polytetraphenylporphyrin iron (II) absorbed on carbon black, Int. J. Hydrogen Energy, 39 (2014) 20171-20182.

[6] M. Mokhtar, M.Z.M. Talib, E.H. Majlan, S.M. Tasirin, W.M.F.W. Ramli, W.R.W. Daud, J. Sahari, Recent developments in materials for aluminum-air batteries: A review, Journal of Industrial and Engineering Chemistry, 32 (2015) 1-20.

[7] Y. Xu, Y. Zhao, J. Ren, Y. Zhang, H. Peng, An All-Solid-State Fiber-Shaped Aluminum-Air Battery with Flexibility, Stretchability, and High Electrochemical Performance, Angew. Chem. Int. Ed. 55 (2016) 7979-7982.

[8] T. Zhang, Z. Li, Z. Zhang, L. Wang, P. Sun, S. Wang, Design of a Three-Dimensional Interconnected Hierarchical Micro-Mesoporous Structure of Graphene as Support Material for Spinel NiCo2O4 Electrocatalysts toward Oxygen Reduction Reaction, J. Phys. Chem. C 122 (2018) 27469-27476.

[9] C. Wang, Z. Li, L. Wang, X. Lu, S. Wang, X. Niu, Vertical-Space-Limit Synthesis of Bifunctional Fe, N-Codoped 2D Multilayer Graphene Electrocatalysts for Zn-Air Battery, Energy Technol. 7 (2019) 1900123.

[10] Y. Li, X. Zhang, H.-B. Li, H.D. Yoo, X. Chi, Q. An, J. Liu, M. Yu, W. Wang, Y. Yao, Mixedphase mullite electrocatalyst for $\mathrm{pH}$-neutral oxygen reduction in magnesium-air batteries, Nano Energy, 27 (2016) 8-16.

[11] A. Zadick, L. Dubau, M. Chatenet, U. Demirci, A. Serov, P. Atanassov, Instability Of Commercial Pt/C And Pd/C Electrocatalysts In Alkaline Media, ECS Trans. 69 (2015) 553-558.

[12] A. Zadick, L. Dubau, N. Sergent, G. Berthomé, M. Chatenet, Huge Instability of Pt/C Catalysts in Alkaline Medium, ACS Catal. 5 (2015) 4819-4824.

[13] Z. Wang, E. Tada, A. Nishikata, Communication-Platinum Dissolution in Alkaline Electrolytes, J. Electrochem. Soc. 163 (2016) C853-C855.

[14] M. Jiang, C. Fu, J. Yang, Q. Liu, J. Zhang, B. Sun, Defect-engineered MnO2 enhancing oxygen reduction reaction for high performance Al-air batteries, Energy Storage Mater. 18 (2019) $34-42$. 
[15] J. Wang, W. Liu, G. Luo, Z. Li, C. Zhao, H. Zhang, M. Zhu, Q. Xu, X. Wang, C. Zhao, Synergistic effect of well-defined dual sites boosting the oxygen reduction reaction, Energy Environ. Sci. 11 (2018) 3375-3379.

[16] C. Zhu, H. Li, S. Fu, D. Du, Y. Lin, Highly efficient nonprecious metal catalysts towards oxygen reduction reaction based on three-dimensional porous carbon nanostructures, Chem. Soc. Rev. 45 (2016) 517-531.

[17] D.-W. Wang, D. Su, Heterogeneous nanocarbon materials for oxygen reduction reaction, Energy Environ. Sci. 7 (2014) 576-591.

[18] F. Li, G.-F. Han, H.-J. Noh, S.-J. Kim, Y. Lu, H.Y. Jeong, Z. Fu, J.-B. Baek, Boosting oxygen reduction catalysis with abundant copper single atom active sites, Energy Environ. Sci. 11 (2018) 2263-2269.

[19] G. Nam, Y. Son, S.O. Park, W.C. Jeon, H. Jang, J. Park, S. Chae, Y. Yoo, J. Ryu, M.G. Kim, A Ternary $\mathrm{Ni}_{46} \mathrm{Co}_{40} \mathrm{Fe}_{14}$ Nanoalloy-Based Oxygen Electrocatalyst for Highly Efficient Rechargeable Zinc-Air Batteries, Adv. Mater. 30 (2018) 1803372.

[20] X. Yang, J. Xu, Z. Chang, D. Bao, Y. Yin, T. Liu, J. Yan, D.P. Liu, Y. Zhang, X. Zhang, Blood-Capillary-Inspired, Free-Standing, Flexible, and Low-Cost Super-Hydrophobic NCNTs@SS Cathodes for High-Capacity, High-Rate, and Stable Li-Air Batteries, Adv. Energy Mater. 8 (2018) 1702242.

[21] Z. Wang, H. Jin, T. Meng, K. Liao, W. Meng, J. Yang, D. He, Y. Xiong, S. Mu, Fe, CuCoordinated ZIF-Derived Carbon Framework for Efficient Oxygen Reduction Reaction and ZincAir Batteries, Adv. Funct. Mater. 28 (2018) 1802596.

[22] C. Tang, Q. Zhang, Can metal-nitrogen-carbon catalysts satisfy oxygen electrochemistry? J. Mater. Chem. A 4 (2016) 4998-5001.

[23] H. Zhang, W. Zhou, T. Chen, B.Y. Guan, Z. Li, X.W.D. Lou, A modular strategy for decorating isolated cobalt atoms into multichannel carbon matrix for electrocatalytic oxygen reduction, Energy Environ. Sci. 11 (2018) 1980-1984.

[24] P. Yin, T. Yao, Y. Wu, L. Zheng, Y. Lin, W. Liu, H. Ju, J. Zhu, X. Hong, Z. Deng, Single Cobalt Atoms with Precise N-Coordination as Superior Oxygen Reduction Reaction Catalysts, Angew. Chem. Int. Ed., 55 (2016) 10800-10805. 
[25] F. Meng, H. Zhong, D. Bao, J. Yan, X. Zhang, In Situ Coupling of Strung $\mathrm{Co}_{4} \mathrm{~N}$ and Intertwined N-C Fibers toward Free-Standing Bifunctional Cathode for Robust, Efficient, and Flexible Zn-Air Batteries, J. Am. Chem. Soc., 138 (2016) 10226-10231.

[26] B.Y. Guan, Y. Lu, Y. Wang, M. Wu, X.W. Lou, Porous Iron-Cobalt Alloy/Nitrogen-Doped Carbon Cages Synthesized via Pyrolysis of Complex Metal-Organic Framework Hybrids for Oxygen Reduction, Adv. Funct. Mater. 28 (2018) 1706738.

[27] W. B, G. D, H. D, G. R, K. K, Driving the oxygen evolution reaction by nonlinear cooperativety in bimetallic coordination catalysts, J. Am. Chem. Soc., 138 (2016) 3623.

[28] W. Wang, J. Luo, W. Chen, J. Li, W. Xing, S. Chen, Synthesis of mesoporous Fe/N/C oxygen reduction catalysts through $\mathrm{NaCl}$ crystallite-confined pyrolysis of polyvinylpyrrolidone, J. Mater. Chem. A 4 (2016) 12768-12773.

[29] H. Hou, C.E. Banks, M. Jing, Y. Zhang, X. Ji, Carbon Quantum Dots and Their Derivative 3D Porous Carbon Frameworks for Sodium-Ion Batteries with Ultralong Cycle Life, Adv. Mater. 27 (2015) 7861-7866.

[30] M. Xiao, J. Zhu, L. Feng, C. Liu, W. Xing, Meso/Macroporous Nitrogen-Doped Carbon Architectures with Iron Carbide Encapsulated in Graphitic Layers as an Efficient and Robust Catalyst for the Oxygen Reduction Reaction in Both Acidic and Alkaline Solutions, Adv. Mater. 27 (2015) 2521-2527.

[31] T. Jing, R.R. Salunkhe, L. Jian, N.L. Torad, I. Masataka, F. Shuhei, Y. Yusuke, Thermal conversion of core-shell metal-organic frameworks: a new method for selectively functionalized nanoporous hybrid carbon, J. Am. Chem. Soc., 137 (2015) 1572.

[32] F. Zheng, Y. Yang, Q. Chen, High lithium anodic performance of highly nitrogen-doped porous carbon prepared from a metal-organic framework, Nature Commun. 5 (2014) 5261.

[33] X. Wang, J. Zhou, H. Fu, W. Li, X. Fan, G. Xin, J. Zheng, X. Li, MOF derived catalysts for electrochemical oxygen reduction, J. Mater. Chem. A 2 (2014) 14064-14070.

[34] Y. He, S. Hwang, D.A. Cullen, M.A. Uddin, L. Langhorst, B. Li, S. Karakalos, A.J. Kropf, E.C. Wegener, J. Sokolowski, M. Chen, D. Myers, D. Su, K.L. More, G. Wang, S. Litster, G. Wu, Highly active atomically dispersed $\mathrm{CoN}_{4}$ fuel cell cathode catalysts derived from surfactantassisted MOFs: carbon-shell confinement strategy, Energy Environ. Sci. 12 (2019) 250-260.

[35] L. Shang, H. Yu, X. Huang, T. Bian, R. Shi, Y. Zhao, G.I.N. Waterhouse, L.Z. Wu, C.H. Tung, T. Zhang, Well-Dispersed ZIF-Derived Co,N-Co-doped Carbon Nanoframes through 
Mesoporous-Silica-Protected Calcination as Efficient Oxygen Reduction Electrocatalysts, Adv. Mater. 28 (2016) 1668-1674.

[36] H. Ning, G. Li, Y. Chen, K. Zhang, Z. Gong, R. Nie, W. Hu, Q. Xia, Porous N-Doped CarbonEncapsulated CoNi Alloy Nanoparticles Derived from MOFs as Efficient Bifunctional Oxygen Electrocatalysts, ACS Appl. Mater. Inter. 11 (2019) 1957-1968.

[37] H. Zhong, J. Wang, Y. Zhang, W. Xu, W. Xing, D. Xu, Y. Zhang, X. Zhang, ZIF-8 Derived Graphene-Based Nitrogen-Doped Porous Carbon Sheets as Highly Efficient and Durable Oxygen Reduction Electrocatalysts, Angew. Chem. Int. Ed., 53 (2014) 14235-14239.

[38] F. Meng, Z. Wang, H. Zhong, J. Wang, J. Yan, X. Zhang, Reactive Multifunctional TemplateInduced Preparation of Fe-N-Doped Mesoporous Carbon Microspheres Towards Highly Efficient Electrocatalysts for Oxygen Reduction, Adv. Mater. 28 (2016) 7948-7955.

[39] S. Gupta, L. Qiao, S. Zhao, H. Xu, Y. Lin, S.V. Devaguptapu, X. Wang, M.T. Swihart, G. Wu, Highly Active and Stable Graphene Tubes Decorated with FeCoNi Alloy Nanoparticles via a Template-Free Graphitization for Bifunctional Oxygen Reduction and Evolution, Adv. Energy Mater. 6 (2016) 1601198.

[40] M.Y. Rafique, L. Pan, W.S. Khan, M.Z. Iqbal, H. Qiu, M.H. Farooq, M. Ellahi, Z. Guo, Controlled synthesis, phase formation, growth mechanism, and magnetic properties of 3-D CoNi alloy microstructures composed of nanorods, CrystEngComm 15 (2013) 5314-5325.

[41] H. Wu, P. Cao, W. Li, N. Ni, L. Zhu, X. Zhang, Microwave-assisted synthesis and magnetic properties of size-controlled CoNi/MWCNT nanocomposites, J. Alloys Compd. 509 (2011) 12611265.

[42] Y. Yang, K. Mao, S. Gao, H. Huang, G. Xia, Z. Lin, P. Jiang, C. Wang, H. Wang, Q. Chen, O-, N-Atoms-Coordinated Mn Cofactors within a Graphene Framework as Bioinspired Oxygen Reduction Reaction Electrocatalysts, Adv. Mater. 30 (2018) 1801732.

[43] T. Palaniselvam, V. Kashyap, S.N. Bhange, J. B. Baek, S. Kurungot, Nanoporous Graphene Enriched with Fe/Co-N Active Sites as a Promising Oxygen Reduction Electrocatalyst for Anion Exchange Membrane Fuel Cells, Adv. Funct. Mater. 26 (2016) 2150-2162.

[44] T. Zhang, Z. Li, L. Wang, P. Sun, Z. Zhang, S. Wang, Spinel $\mathrm{MnCo}_{2} \mathrm{O}_{4}$ Nanoparticles Supported on Three-Dimensional Graphene with Enhanced Mass Transfer as an Efficient Electrocatalyst for the Oxygen Reduction Reaction, ChemSusChem 11 (2018) 2730-2736. 
[45] S. Li, C. Cheng, H.-W. Liang, X. Feng, A. Thomas, 2D Porous Carbons prepared from Layered Organic-Inorganic Hybrids and their Use as Oxygen-Reduction Electrocatalysts, Adv. Mater. 29 (2017) 1700707.

[46] K. Niu, B. Yang, J. Cui, J. Jin, X. Fu, Q. Zhao, J. Zhang, Graphene-based non-noble-metal $\mathrm{Co} / \mathrm{N} / \mathrm{C}$ catalyst for oxygen reduction reaction in alkaline solution, J. Power Sources 243 (2013) $65-71$.

[47] L. Wang, S. Dou, J. Xu, H.K. Liu, S. Wang, J. Ma, S.X. Dou, Highly nitrogen doped carbon nanosheets as an efficient electrocatalyst for the oxygen reduction reaction, Chem. Commun. 51 (2015) 11791-11794.

[48] A. Sivanantham, P. Ganesan, L. Estevez, B.P. McGrail, R.K. Motkuri, S. Shanmugam, A Stable Graphitic, Nanocarbon-Encapsulated, Cobalt-Rich Core-Shell Electrocatalyst as an Oxygen Electrode in a Water Electrolyzer, Adv. Energy Mater. 8 (2018) 1702838.

[49] P. Cai, Y. Hong, S. Ci, Z. Wen, In situ integration of CoFe alloy nanoparticles with nitrogendoped carbon nanotubes as advanced bifunctional cathode catalysts for $\mathrm{Zn}$-air batteries, Nanoscale 8 (2016) 20048-20055.

[50] H. Hwang, T. Kwon, H.Y. Kim, J. Park, A. Oh, B. Kim, H. Baik, S.H. Joo, K. Lee, Ni@Ru and NiCo@Ru Core-Shell Hexagonal Nanosandwiches with a Compositionally Tunable Core and a Regioselectively Grown Shell, Small 14 (2018) 1702353.

[51] A. Mayoral, S. Mejía-Rosales, M.M. Mariscal, E. Pérez-Tijerina, M. José-Yacamán, The CoAu interface in bimetallic nanoparticles: a high resolution STEM study, Nanoscale 2 (2010) 26472651.

[52] M.M. Mariscal, A. Mayoral, J. Olmos-Asar, C. Magen, S. Mejía-Rosales, E. Pérez-Tijerina, M. Jose-Yacaman, Nanoalloying in real time. A high resolution STEM and computer simulation study, Nanoscale 3 (2011) 5013-5019.

[53] Rodrigo Esparza, Alan Santoveña, Alvaro Ruíz-Baltazar, Alvaro Angeles-Pascual, Daniel Bahena, Jose Maya-Cornejo, Janet Ledesma-García, R. Pérez, Study of PtPd Bimetallic Nanoparticles for Fuel Cell Applications, Mater. Res. 20 (2017) 1193-1200.

[54] I.S. Amiinu, X. Liu, Z. Pu, W. Li, Q. Li, J. Zhang, H. Tang, H. Zhang, S. Mu, From 3D ZIF Nanocrystals to Co-N $\mathrm{N}_{\mathrm{x}} / \mathrm{C}$ Nanorod Array Electrocatalysts for ORR, OER, and Zn-Air Batteries, Adv. Funct. Mater. 28 (2018) 1704638. 
[55] Y. Hou, S. Cui, Z. Wen, X. Guo, X. Feng, J. Chen, Strongly Coupled 3D Hybrids of N-doped Porous Carbon Nanosheet/CoNi Alloy-Encapsulated Carbon Nanotubes for Enhanced Electrocatalysis, Small 11 (2015) 5940-5948.

[56] X. Fu, Y. Liu, X. Cao, J. Jin, Q. Liu, J. Zhang, FeCo-N $\mathrm{N}_{\mathrm{x}}$ embedded graphene as high performance catalysts for oxygen reduction reaction, Appl. Catal., B 130-131 (2013) 143-151.

[57] J. Li, S. Mao, Y. Hou, L. Lei, C. Yuan, 3D Edge-Enriched Fe 3 C C Nanocrystals with a Core-Shell Structure Grown on Reduced Graphene Oxide Networks for Efficient Oxygen Reduction Reaction, ChemSusChem 11 (2018) 3292-3298.

[58] L. Liu, G. Zeng, J. Chen, L. Bi, L. Dai, Z. Wen, N-doped porous carbon nanosheets as pHuniversal ORR electrocatalyst in various fuel cell devices, Nano Energy 49 (2018) 393-402.

[59] J. Masa, W. Xia, M. Muhler, W. Schuhmann, On the role of metals in nitrogen-doped carbon electrocatalysts for oxygen reduction, Angew. Chem. Int. Ed. 54 (2015) 10102-10120.

[60] M.S. Mikkola, T. Rockward, F.A. Uribe, B.S. Pivovar, The effect of $\mathrm{NaCl}$ in the cathode air stream on PEMFC performance, Fuel Cells 7 (2007) 153-158.

[61] W. Song, Z. Chen, C. Yang, Z. Yang, J. Tai, Y. Nan, H. Lu, Carbon-coated, methanol-tolerant platinum/graphene catalysts for oxygen reduction reaction with excellent long-term performance, J. Mater. Chem. A 3 (2015) 1049-1057.

[62] B.S. Yeo, A.T. Bell, Enhanced activity of gold-supported cobalt oxide for the electrochemical evolution of oxygen, J. Am. Chem. Soc. 133 (2011) 5587-5593.

[63] H. Zhong, K.H. Ly, M. Wang, Y. Krupskaya, X. Han, J. Zhang, J. Zhang, V. Kataev, B. Büchner, I.M. Weidinger, S. Kaskel, P. Liu, M. Chen, R. Dong, X. Feng, A Phthalocyanine-Based Layered Two-Dimensional Conjugated Metal-Organic Framework as a Highly Efficient Electrocatalyst for the Oxygen Reduction Reaction, Angew. Chem. Int. Ed. 58 (2019) 1067710682.

[64] T. Pauporte, L. Mendoza, M. Cassir, M. Bernard, J. Chivot, Direct low-temperature deposition of crystallized CoOOH films by potentiostatic electrolysis, J. Electrochem. Soc. 152 (2005) C49C53.

[65] D. Hollmann, N. Rockstroh, K. Grabow, U. Bentrup, J. Rabeah, M. Polyakov, A.E. Surkus, W. Schuhmann, S. Hoch, A. Brückner, From the Precursor to the Active State: Monitoring Metamorphosis of Electrocatalysts During Water Oxidation by In Situ Spectroscopy, ChemElectroChem 4 (2017) 2117-2122. 
[66] K. Cole, D. Kirk, S. Thorpe, In Situ Raman Study of Amorphous and Crystalline Ni-Co Alloys for the Alkaline Oxygen Evolution Reaction, J. Electrochem. Soc. 165 (2018) J3122-J3129.

[67] Z. Chen, L. Cai, X. Yang, C. Kronawitter, L. Guo, S. Shen, B.E. Koel, Reversible Structural Evolution of $\mathrm{NiCoO}_{\mathrm{x}} \mathrm{H}_{\mathrm{y}}$ during the Oxygen Evolution Reaction and Identification of the Catalytically Active Phase, ACS Catal. 8 (2018) 1238-1247.

[68] G. K. Ramesha and S. Sampath, Electrochemical Reduction of Oriented Graphene Oxide Films: An in Situ Raman Spectroelectrochemical Study, J. Phys. Chem. C, 113 (2009) 7985-7989. [69] J.K. Nørskov, J. Rossmeisl, A. Logadottir, L. Lindqvist, J.R. Kitchin, T. Bligaard, H. Jonsson, Origin of the overpotential for oxygen reduction at a fuel-cell cathode, J. Phys. Chem. B 108 (2004) 17886-17892. 